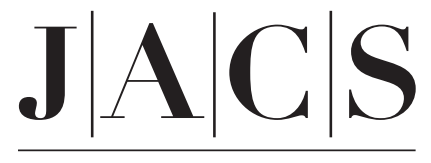

A R T I C L E S

Published on Web 12/07/2006

\title{
Fe L-Edge X-ray Absorption Spectroscopy of Low-Spin Heme Relative to Non-heme Fe Complexes: Delocalization of Fe d-Electrons into the Porphyrin Ligand
}

\author{
Rosalie K. Hocking, ${ }^{\dagger}$ Erik C. Wasinger, ${ }^{\dagger}$ Yi-Long Yan $^{\dagger}{ }^{+}$Frank M. F. deGroot, ${ }^{\ddagger}$ \\ F. Ann Walker,§ Keith O. Hodgson, ${ }^{*},, \#$ Britt Hedman,, ${ }^{*}, \#$ and Edward I. Solomon*,† \\ Contribution from the Department of Chemistry, Stanford University, Stanford, California \\ 94305, Department of Inorganic Chemistry and Catalysis, Utrecht University, Sorbonnelaan 16, \\ 3584, The Netherlands, Department of Chemistry, The University of Arizona, Tucson, Arizona \\ 85721, and Stanford Synchrotron Radiation Laboratory, SLAC, Stanford University, \\ Stanford, California 94309
}

Received August 3, 2006

\begin{abstract}
Hemes (iron porphyrins) are involved in a range of functions in biology, including electron transfer, small-molecule binding and transport, and $\mathrm{O}_{2}$ activation. The delocalization of the $\mathrm{Fe}$ d-electrons into the porphyrin ring and its effect on the redox chemistry and reactivity of these systems has been difficult to study by optical spectroscopies due to the dominant porphyrin $\pi \rightarrow \pi^{*}$ transitions, which obscure the metal center. Recently, we have developed a methodology that allows for the interpretation of the multiplet structure of Fe L-edges in terms of differential orbital covalency (i.e., differences in mixing of the d-orbitals with ligand orbitals) using a valence bond configuration interaction (VBCl) model. Applied to low-spin heme systems, this methodology allows experimental determination of the delocalization of the Fe d-electrons into the porphyrin $(\mathrm{P})$ ring in terms of both $\mathrm{P} \rightarrow \mathrm{Fe} \sigma$ and $\pi$-donation and $\mathrm{Fe} \rightarrow \mathrm{P} \pi$ back-bonding. We find that $\pi$-donation to $\mathrm{Fe}(\mathrm{III})$ is much larger than $\pi$ back-bonding from $\mathrm{Fe}(\mathrm{II})$, indicating that a hole superexchange pathway dominates electron transfer. The implications of the results are also discussed in terms of the differences between heme and non-heme oxygen activation chemistry.
\end{abstract}

\section{Introduction}

Heme (iron porphyrin) sites are involved in a range of biological functions, including electron transfer (e.g., cytochromes $a, b, c$, and $f),{ }^{1-3}$ in which the hemes cycle between low-spin $\mathrm{Fe}(\mathrm{II})$ and low-spin $\mathrm{Fe}(\mathrm{III})$, small-molecule binding and transport, ${ }^{4,5}$ catalysis, and $\mathrm{O}_{2}$ activation (e.g., peroxidases and cytochromes P450), ${ }^{6-11}$ where high-valent Fe centers are

† Stanford University.

¿ Utrecht University.

$\S$ The University of Arizona.

\# Stanford Synchrotron Radiation Laboratory.

(1) Rodgers, K. R.; Lukat-Rodgers, G. S. In Comprehensive Coordination Chemistry II; McCleverty, J. A., Meyer, T. J., Eds.; Elsevier Pergamon: Amsterdam, 2004

(2) Kadish, K. M.; Caemelbecke, E. V.; Royal, R. In The Porphyrin Handbook; Kadish, K. M., Smith, K . M., Guilard, R., Eds.; Academic Press: San Diego, CA, 2000; Vol. 8(55), pp 1-97.

(3) Fukuzumi, S. In The Porphyrin Handbook; Kadish, K. M., Smith, K. M., Guilard, R., Eds.; Academic Press: San Diego, CA, 2000; Vol. 8(56), pp 115-146.

(4) Collman, J. P.; Fu, L. Acc. Chem. Res. 1999, 32, 455-463.

(5) Walker, F. A. J. Inorg. Biochem. 2005, 99, 216-236.

(6) Bhaskar, B.; Lad, L.; Poulos, T. L. In Encylopedia of Inorganic Chemistry; King, R. B., Ed.; Wiley \& Sons, Ltd.: Chichester, 2005; pp 1-21.

(7) Poulos, T. L. In The Porphyrin Handbook; Kadish, K. M., Smith, K. M. Guilard R., Eds.; Academic Press: San Diego, CA, 2000; Vol. 4(32), pp $189-215$.

(8) Sundaramoorthy, M.; Terner, J.; Poulos, T. L. Struct. Bonding 1995, 3, $1367-1378$

(9) Libby, R. D.; Beachy, T. M.; Phipps, A. K. J. Biol. Chem. 1996, 271, $21820-21827$

(10) Dunford, H. B.; Lambeir, A. M.; Kashem, M. A.; Pickard, M. Arch. Biochem. Biophys. 1987, 252, 292-302

10.1021/ja065627h CCC: $\$ 37.00 \odot 2007$ American Chemical Society involved in $\mathrm{H}$ atom abstraction, hydroxylation, and epoxide formation. Heme sites are fundamentally different from nonheme iron sites in that the porphyrin ligand allows for the delocalization of the iron d-electrons into the porphyrin $\pi$ system. ${ }^{12-14}$ This changes the nature of the $\mathrm{Fe}$ in terms of the flexibility of the central coordination site, the energetics of reactivity, and its function in electron transfer (ET). ${ }^{11}$

Heme enzymes have been easier to study than non-heme Fe enzymes because of the intense characteristic porphyrin $\pi \rightarrow \pi^{*}$ transitions. However, these transitions have made studying the metal center difficult because they obscure many of the spectral properties of the Fe sites. A good example of this difficulty is reflected in the differences in understanding of the Fe sites in two classes of $\mathrm{O}_{2}$ transport proteins, hemerythrin ${ }^{15,16}$ (non-heme) and hemoglobin ${ }^{17-19}$ (heme). The binuclear Fe site of oxyhemerythrin can be clearly assigned as a hydroperoxide bound

(11) Sono, M.; Roach, M. P.; Coulter, E. D.; Dawson, J. H. Chem. Rev. 1996, 96, 2841-2887.

(12) Neidig, M. L.; Solomon, E. I. Chem. Commun. 2005, 47, 5843-5863.

(13) Solomon, E. I.; Brunhold, T. C.; Davis, M. I.; Kemsley, J. N.; Lee, S.-K.; Lehnert, N.; Neese, F.; Skulan, A.; Yang, Y.-S.; Zhou, J. Chem. Rev. 2000 $100,235-349$.

(14) Que, L. Jr. J. Biol. Inorg. Chem. 2004, 9, 684-690.

(15) Brunold, T. C.; Solomon, E. I. J. Am. Chem. Soc. 1999, 121, 8288-8295.

(16) Brunold, T. C.; Solomon, E. I. J. Am. Chem. Soc. 1999, 121, 8277-8287.

(17) Kaupp, M.; Rovira, C.; Parinello, M. J. Phys. Chem. B 2000, 104, 52005208.

(18) Collman, J. P.; Boulatov, R.; Sunderland, C. J.; Fu, L. Chem. Rev. 2004, 104, 561-588.

(19) Bytheway, I.; Hall, M. B. Chem. Rev. 1994, 94, 639-658

J. AM. CHEM. SOC. 2007, 129, 113-125

113 
to a binuclear $\mathrm{Fe}(\mathrm{III})$ center by a range of spectroscopies. ${ }^{15,16}$ In contrast, there has been significant controversy over the assignment of the electron distribution between the $\mathrm{Fe}$ and the $\mathrm{O}_{2}$ in oxyhemoglobin. ${ }^{4,20-28}$

Spectroscopic methods that have been used to probe the electron distribution in the d-orbitals of ferro- and ferriheme systems include nuclear magnetic resonance (NMR), ${ }^{29,30}$ electron paramagnetic resonance (EPR), and Mössbauer. ${ }^{31-33}$ In systems with a low-spin Fe(III) center, EPR is able to probe the energy splitting of the $\mathrm{d}_{x y^{-}}, \mathrm{d}_{x z^{-}}$, and $\mathrm{d}_{y z^{-}}$-orbitals ${ }^{34,35}$ and can thus provide insight into the $\pi$-donation of the heme center compared to that of axial ligands. ${ }^{36-38}$ While significant insight can be obtained using EPR spectroscopy, the interpretation of the $g$ values in terms of orbital energies is complicated due to the effects of covalency on the spin-orbital coupling. ${ }^{39}$ While EPR or Mössbauer spectroscopy ${ }^{40}$ can provide an assignment of the splitting patterns of the $\mathrm{d}_{\pi}$-orbital set, there is still no direct probe of the relative effects of covalency and ligand field. The NMR spectra of low-spin Fe(III) provide evidence for significant $\pi$-donation from the porphyrin ring to the Fe and evidence for little back-bonding. ${ }^{29,30,41,42}$ No spectroscopic approach has simultaneously provided substantial information about the bonding and back-bonding in low-spin Fe(II) porphyrins. These interactions in both redox states are of key importance in identifying ET pathways in the cytochromes and contribute directly to $\mathrm{O}_{2}$ activation in a number of heme enzymes.

Fe L-edge X-ray absorption spectroscopy (XAS) provides a number of key probes of bonding that are not available using other experimental techniques. An L-edge is composed of an $\mathrm{L}_{1}$-edge, the $2 \mathrm{~s} \rightarrow 3 \mathrm{~d}$ transition, and the $\mathrm{L}_{2,3}$-edges, the $2 \mathrm{p} \rightarrow 3 \mathrm{~d}$ transition split by final state spin-orbit coupling into the ${ }^{2} \mathrm{P}_{3 / 2}\left(\mathrm{~L}_{3}\right)$ and the ${ }^{2} \mathrm{P}_{1 / 2}\left(\mathrm{~L}_{2}\right)$ edges. The first of these edges $\left(\mathrm{L}_{1}\right)$ is electric dipole forbidden and, as a consequence, has very little intensity compared to the $\mathrm{L}_{2,3}$-edges, which are electric dipole allowed and have greater intensity. Thus, L-edge spectroscopy both generally and herein refers to transitions to the $\mathrm{L}_{2,3^{-}}$

(20) Jenson, K. P.; Roos, B. O.; Ryde, U. J. Inorg. Biochem. 2005, 99, 45-54. (21) Jenson, K. P.; Ryde, U. J. Biol. Chem. 2004, 279, 14561-14569.

(22) Pauling, L. Proc. Natl. Acad. Sci. U.S.A. 1977, 74, 2612-2613.

(23) Pauling, L.; Coryell, C. D. Proc. Natl. Acad. Sci. U.S.A. 1936, 22, 210-215.

(24) Goddard, W. A.; Olafson, B. D. Proc. Nat. Acad. Sci. U.S.A. 1975, 72, $2335-2339$

(25) Olafson, B. D.; Goddard, W. A. Proc. Natl. Acad. Sci. U.S.A. 1977, 74 $1315-1319$

(26) Case, D. A.; Huynh, B. H.; Karplus, M. J. Am. Chem. Soc. 1979, 101, 4433-4453

(27) Rovira, C.; Parrinello, M. Biophys. J. 2000, 78, 93-100.

(28) Yamamoto, S.; Kashiwagi, H. Chem. Phys. Lett. 1993, 205, 306-312.

(29) Walker, F. A. In The Porphyrin Handbook; Kadish, K. M., Smith, K. M., Guilard, R., Eds.; San Diego, CA, 2000; Vol. 5(36), pp 81-183.

(30) Walker, F. A. Inorg. Chem. 2003, 42, 4526-4544.

(31) Sharrock, M.; Debrunner, P. G.; Schulz, C.; Lipscomb, J. D.; Marshall, V.; Gunsalus, I. C. Biochim. Biophys. Acta 1976, 420, 8-26.

(32) Huynh, B. H.; Emptage, M. H.; Münck, E. Biochim. Biophys. Acta 1978, 534, 295-306.

(33) Rhynard, D.; Lang, G.; Spartalian, K.; Yonetani, T. J. Chem. Phys. 1979, 71, 3715-3721.

(34) Griffith, J. S. Mol. Phys 1971, 21, 135-139.

(35) Taylor, C. P. S. Biochim. Biophys. Acta 1977, 491, 137-149.

(36) Walker, F. A.; Huynh, B. H.; Scheidt, W. R.; Osvath, S. R. J. Am. Chem. Soc. 1986, 108, 5288-5297.

(37) Scheidt, W. R.; Kirner, J. F.; Hoard, J. L.; Reed, C. A. J. Am. Chem. Soc. 1987, 109, 1963-1968.

(38) Martinez, S. E.; Huang, D.; Ponomarev, M.; Cramer, W. A.; Smith, J. L. Protein Sci. 1996, 5, 1081-1092.

(39) Neese, F.; Solomon, E. I. Inorg. Chem. 1998, 37, 6568-6582.

(40) Oosterhuis, W. T.; Lang, G. Phys. Rev. 1969, 178, 439-456.

(41) Walker, F. A. Coord. Chem. Rev. 1999, 185-186, 471-534.

(42) La Mar, G. N.; Walker, F. A. In The Porphyrins; Dolphin, D., Ed.; Academic Press: New York, 1979; Vol. IV, pp 61-157. edge. ${ }^{43,44}$ Given that the 2 p-orbital is localized on the $\mathrm{Fe}, \mathrm{Fe}$ $\mathrm{L}_{2,3}$-edge intensity is directly proportional to the Fe d-character in the unoccupied valence orbitals of the metal. ${ }^{45-48}$ In addition, the energy shift of the L-edge has contributions from $Z_{\text {eff }}$ of the metal and the ligand field splitting of its d-orbitals. Finally, the L-edge spectral shape is sensitive to both the ligand field and covalency (vide infra), but these are complicated by $2 \mathrm{p}^{5}$ $3 \mathrm{~d}^{N+1}$ multiplet effects similar to the effects described by the Tanabe-Sugano ${ }^{49}$ matrices and diagrams for $\mathrm{d}^{N}$ ground states. ${ }^{48,50}$

The sum of these contributions to the spectra can be calculated using the ligand field multiplet model implemented by Thole..$^{51}$ In early versions of the model, the effect of covalent delocalization on the L-edge was only accounted for by the reduction of the Slater integrals associated with electron repulsion (by $\kappa$ $<0.8) .{ }^{52-54}$ Later versions of the model included first the effects of donor covalency through ligand-to-metal charge transfer $(\mathrm{LMCT})^{55}$ and later acceptor covalency through metal-to-ligand charge transfer (MLCT) ${ }^{56-58}$ These models explicitly allowed each symmetry set of $\mathrm{d}^{N}$ and $\mathrm{d}^{N+1} \mathrm{~L}$ (where $\mathrm{L}=$ ligand hole) in the case of LMCT, or $\mathrm{d}^{N}$ and $\mathrm{d}^{N-1} \mathrm{~L}^{-}$(where $\mathrm{L}^{-}=$ligand plus an electron) in the case of MLCT configurations, to mix using a valence bond configuration interaction (VBCI) model. Recently, we have adapted the model to simultaneously include the effects of both LMCT (donor) and MLCT (back-bonding) on spectral shape. ${ }^{50}$

A methodology has been developed, ${ }^{48}$ based on multiplet simulations, that enables the determination of the covalent delocalization of the different symmetry sets of d-orbitals, called differential orbital covalency (DOC). The technique has been successfully applied to systems where both ligand-to-metal donation and metal-to-ligand back-bonding are present. ${ }^{48,50}$ Herein, we examine the Fe L-edge spectra of low-spin Fe(II) and $\mathrm{Fe}(\mathrm{III})$ heme compounds $\left[\mathrm{Fe}(\mathrm{tpp})(\mathrm{ImH})_{2}\right]$ and $[\mathrm{Fe}(\mathrm{tpp})$ $\left.(\mathrm{ImH})_{2}\right] \mathrm{Cl}$ to experimentally determine the valence delocalization of the Fe d-electrons into the porphyrin orbitals. These spectra are compared to those obtained from the low-spin reference compounds $\left[\mathrm{Fe}(\operatorname{tacn})_{2}\right] \mathrm{Cl}_{2} / \mathrm{Cl}_{3}$ with no $\pi$ bonding, allowing a quantitative determination of the differences between

(43) Wang, H.; Peng, G.; Miller, L. M.; Scheuring, E. M.; George, S. J.; Chance, M. R.; Cramer, S. P. J. Am. Chem. Soc. 1997, 119, 4921-4928.

(44) Tobias, F.; Weiwei, G.; Friedrich, S.; Wang, H.; Gencic, S.; Grahame, D. A.; Cramer, S. P. J. Am. Chem. Soc. 2004, 126, 88-95.

(45) George, S. J.; Lowery, M. D.; Solomon, E. I.; Cramer, S. P. J. Am. Chem. Soc. 1993, 115, 2968-2969.

(46) Kotani, A.; Okada, K. Tech. Rep. ISSP, Ser. A 1992, 2562.

(47) van der Laan, G.; Zaanen, J.; Sawatzky, G. A.; Karnatak, R.; Esteva, J. M. Phys. Rev. B 1986, 33, 4253-4263.

(48) Wasinger, E. C.; deGroot, F. M. F.; Hedman, B.; Hodgson, K. O.; Solomon, E. I. J. Am. Chem. Soc. 2003, 125, 12894-12906.

(49) Sugano, S.; Tanabe, Y. Multiplets of transition-metal ions in crystals; Academic Press: New York, 1970.

(50) Hocking, R. K.; Wasinger, E. C.; deGroot, F. M. F.; Hodgson, K. O.; Hedman, B.; Solomon, E. I. J. Am. Chem. Soc. 2006, 128, 10442-10451.

(51) Thole, B. T.; van der Laan, G.; Fuggle, J. C.; Sawatzky, G. A.; Karanatak, R. C.; Esteva, J.-M. Phys. Rev. B 1985, 32, 5107-5118.

(52) de Groot, F. M. F.; Fuggle, J. C.; Thole, B. T.; Sawatzky, G. A. Phys. Rev. $B$ 1990, 42, 5459-5468.

(53) deGroot, F. M. F.; Fuggle, J. C.; Thole, B. T.; Sawatzky, G. A. Phys. Rev. $B$ 1990, 41, 928-238.

(54) Van der laan, G.; Thole, B. T.; Sawatzky, G. A.; Verdaguer, M. Phys. Rev. B 1988, 37, 6587-6589.

(55) deGroot, F. M. F. Coord. Chem. Rev. 2005, 249, 31-63.

(56) Arrio, M.-A.; Sianctavit, Ph.; Cartier dit Moulin, Ch.; Mallah, T.; Verdaguer, M.; Pellegrin, E.; Chen, C. T. J. Am. Chem. Soc. 1996, 118, 6422-6427.

(57) Arrio, M.-A.; Scuiller, A.; Sainctavit, Ph.; Cartier dit Moulin, Ch.; Mallah, T.; Verdaguer, M. J. Am. Chem. Soc. 1999, 121, 6414-6420.

(58) Cartier dit Moulin, Ch.; Villain, F.; Bleuzen, A.; Arrio, M. A.; Sainctavit, C.; Lomenech, C.; Escax, V.; Baudelet, F.; Dartyge, E.; Gallet, J. J.; Verdaguer, M. J. Am. Chem. Soc. 2000, 122, 6653-6658. 
heme and non-heme Fe site electronic structures that contribute to differences in reactivity.

\section{Experimental Section}

Samples. The compounds $\left[\mathrm{Fe}(\mathrm{tpp})(\mathrm{ImH})_{2}\right] \mathrm{Cl}$ and $\left[\mathrm{Fe}(\operatorname{tpp})(\operatorname{ImH})_{2}\right]$ were synthesized according to published methods. ${ }^{59-61}$ Samples were finely ground, spread across double-sided adhesive conductive graphite tape, and attached to a copper paddle, aligned $45^{\circ}$ to the incident beam as described previously. ${ }^{48,62}$ These conditions result in isotropic $\mathrm{L}_{2,3^{-}}$ edge spectra.

XAS Data Collection and Reduction. X-ray absorption spectra were recorded at the Stanford Synchrotron Radiation Laboratory (SSRL) on the 31-pole wiggler beam line 10-1 under ring operating conditions of 50-100 $\mathrm{mA}$ and $3 \mathrm{GeV}$. The radiation was dispersed using a spherical grating monochromator set at 1000 lines $/ \mathrm{mm}$ and $20 \mu \mathrm{m}$ entrance and exit slits ( $0.15 \mathrm{eV}$ resolution). All measurements were made at $20 \pm 5$ ${ }^{\circ} \mathrm{C}$. Sample measurement was performed using the total electron yield mode, where the sample signal $\left(\mathrm{I}_{1}\right)$ was collected with a Galileo 4716 channeltron electron multiplier aligned $45^{\circ}$ relative to the copper paddle and $90^{\circ}$ to the incident beam. The signal was flux normalized $\left(I_{1} / I_{0}\right)$ by the photocurrent of a gold-grid reference monitor $\left(I_{0}\right)$. Data for all samples were recorded in a sample chamber maintained at $<1 \times 10^{-5}$ Torr, isolated from the UHV beam line by a $1000 \AA$ diamond window. The photon energy was calibrated from the Fe L-edge spectrum of powdered $\alpha-\mathrm{Fe}_{2} \mathrm{O}_{3}$ (hematite) $(<5 \mu \mathrm{m})$ run at intervals between scans. The second feature in the $\mathrm{L}_{3}$-edge and the first feature in the $\mathrm{L}_{2}$-edge were calibrated to 708.5 and $720.1 \mathrm{eV}$, respectively. Data were taken over the range $670-830 \mathrm{eV}$ to permit normalization, as described previously. ${ }^{48}$ A step size of $0.1 \mathrm{eV}$ was used over the edge region (700$730 \mathrm{eV}$ ), and $0.5 \mathrm{eV}$ steps over the remaining regions. The total scan took $\sim 10 \mathrm{~min}, 4 \mathrm{~min}$ over the region $700-730 \mathrm{eV}$. No photoreduction was observed during that time in any of the samples described herein. A function of the form absorption $=\left[\tan ^{-1}\left(k\left(\right.\right.\right.$ energy $\left.\left.-I_{1}\right)+\pi / 2\right)(2 /$ $3)(1 / \pi)]+\left[\tan ^{-1}\left(k\left(\right.\right.\right.$ energy $\left.\left.\left.-I_{2}\right)+\pi / 2\right)(1 / 3)(1 / \pi)\right]$, where $k=0.295$, obtained by experimental fit, ${ }^{48,63}$ and $\mathrm{I}_{2}=\mathrm{I}_{1}+12.3 \mathrm{eV}$ (energy split by spin orbit coupling), was used to model the $\mathrm{L}_{3}$ - and $\mathrm{L}_{2}$-edge jumps, as described previously. ${ }^{48}$ The absolute energy of the arctangent was estimated on the basis of a fit to the L-edge experiment. The $\mathrm{L}_{3}$ intensity reported here is defined after normalization to be between 700 and $715 \mathrm{eV}$ for $\left[\mathrm{Fe}(\operatorname{tacn})_{2}\right] \mathrm{Cl}_{2} /\left[\mathrm{Fe}(\mathrm{tpp})(\mathrm{ImH})_{2}\right]$ and between 701 and $716 \mathrm{eV}$ for $\left[\mathrm{Fe}(\operatorname{tacn})_{3}\right] \mathrm{Cl}_{3} /\left[\mathrm{Fe}(\operatorname{tpp})(\operatorname{ImH})_{2}\right] \mathrm{Cl}$, and the $\mathrm{L}_{2}$ intensity is defined after normalization to be between 715 and $730 \mathrm{eV}$ for [Fe$\left.(\operatorname{tacn})_{2}\right] \mathrm{Cl}_{2} /\left[\mathrm{Fe}(\operatorname{tpp})(\mathrm{ImH})_{2}\right]$ and between 716 and $731 \mathrm{eV}$ for $\left[\mathrm{Fe}(\operatorname{tacn})_{2}\right]-$ $\mathrm{Cl}_{3} /\left[\mathrm{Fe}(\mathrm{tpp})(\mathrm{ImH})_{2}\right] \mathrm{Cl}$. The error reported represents the range of integrated intensities based on at least three repeat measurements of the same spectrum on different dates.

Ligand field multiplet calculations were performed using the multiplet model implemented by Thole,${ }^{51}$ the atomic theory developed by Cowan, ${ }^{64}$ and the crystal field (i.e., symmetry) interactions by described Butler. ${ }^{65}$ This approach includes both electronic Coulomb interactions and spin-orbit coupling for each sub-shell. ${ }^{56,66}$ To simulate the spectra, the Slater-Condon-Shortley parameters $F_{i}$ and $G_{i}$ were first reduced to $80 \%$ of their Hartree-Fock calculated values to account for the over-estimation of electron-electron repulsion found in calcula-

(59) Collman, J. P.; Hoard, J. L.; Kim, N.; Lang, G.; Reed, C. A. J. Am. Chem. Soc. 1975, 97, 2676-2681.

(60) Landrum, J.; Coppens, P.; Naiyin, N. Inorg. Chem. 1988, 27, 482-488.

(61) Scheidt, W. R.; Osvath, S. R.; Lee, Y. J. J. Am. Chem. Soc. 1987, 109, 1958-1963.

(62) DeBeer George, S.; Metz, M.; Szilagyi, R. K.; Wang, H.; Cramer, S. P.; Lu, Y.; Tolman, W. B.; Hedman, B.; Hodgson, K. O.; Solomon, E. I. J. Am. Chem. Soc. 2001, 123, 5757-5767.

(63) Yeh, J. J.; Lindau, I. At. Data Nucl. Data Tables 1985, 32, 1-155.

(64) Cowan, R. D. The Theory of Atomic Structure and Spectra; University of California Press: Berkeley, CA, 1981.

(65) Butler, P. H. Point Group Symmetry Applications: Methods and Tables; Plenum Press: New York, 1981.

(66) van der Laan, G.; Kirkman, I. W. J. Phys.: Condens. Matter 1992, 4, 41894204. tions of the free ion, i.e., $\kappa=0.8$ in nomenclature used elsewhere. ${ }^{56-58}$ The spectrum is calculated from the sum of all possible transitions for an electron excited from the $2 \mathrm{p}$ level into a $3 \mathrm{~d}$ level. ${ }^{67}$ In the ligand field limit, the ground state is approximated by a single electronic configuration $\mathrm{d}^{N}$ split in energy by a crystal field potential in $D_{4 h}$ symmetry, defined by the parameters Dq, Ds, and Dt where the relationship between the orbital energies the crystal field parameters is $b_{1 g}\left(\mathrm{~d}_{x^{2}-y^{2}}\right)=6 \mathrm{Dq}+2 \mathrm{Ds}-1 \mathrm{Dt}, a_{1 g}\left(\mathrm{~d}_{z^{2}}\right)=6 \mathrm{Dq}-2 \mathrm{Ds}-6 \mathrm{Dt}, b_{2 g}$ $\left(\mathrm{d}_{x y}\right)=-4 \mathrm{Dq}+2 \mathrm{Ds}-1 \mathrm{Dt}$, and $e_{g}\left(\mathrm{~d}_{x z} / \mathrm{d}_{y z}\right)=-4 \mathrm{Dq}-1 \mathrm{Ds}+4 \mathrm{Dt} .{ }^{66,68}$ To avoid confusion, any time $D_{4 h}$ symmetry is used, we will indicate it, for example, by $e_{g}\left(D_{4 h}\right)$. Covalent mixing of the metal valence d-orbitals with the ligand valence p-orbitals is simulated using a chargetransfer model, which in the case of LMCT adds a $\mathrm{d}^{N+1} \mathrm{~L}$ configuration above the $\mathrm{d}^{N}$ ground state. The $\mathrm{d}^{N+1} \mathrm{~L}$ configuration is set at an energy $\Delta$ above the $\mathrm{d}^{N}$ configuration, and these two states are coupled by configuration interaction (CI), represented by the mixing term $T_{i}=$ $\left\langle 3 \mathrm{~d}^{N}|h| \mathrm{d}^{N+1} \mathrm{~L}\right\rangle$, where $h$ is the molecular Hamiltonian and $T_{i}$ is proportional to metal-ligand overlap for each of the $i$ symmetry blocks. For a donor ligand system, the ground and LMCT states are $\Psi_{\mathrm{GS}, \mathrm{B}}=$ $\alpha_{1}\left|3 \mathrm{~d}^{N}\right\rangle+\beta_{1}\left|3 \mathrm{~d}^{N+1} \underline{L}\right\rangle$ and $\Psi_{\mathrm{GS}, \mathrm{AB}}=\beta_{1}\left|3 \mathrm{~d}^{M}\right\rangle-\alpha_{1}\left|3 \mathrm{~d}^{N+1} \mathrm{~L}\right\rangle$, respectively, and the L-edge excited states are $\Psi_{\mathrm{ES}, \mathrm{B}}=\alpha_{2}\left|2 \mathrm{p}^{5} 3 \mathrm{~d}^{N+1}\right\rangle+\beta_{2}\left|2 \mathrm{p}^{5} 3 \mathrm{~d}^{N+2} \underline{L}\right\rangle$ and $\Psi_{\mathrm{ES}, \mathrm{AB}}=\beta_{2}\left|2 \mathrm{p}^{5} 3 \mathrm{~d}^{N+1}\right\rangle-\alpha_{2} \mid 2 \mathrm{p}^{5} 3 \mathrm{~d}^{N+2} \underline{\mathrm{L}\rangle}$, where the coefficients $\alpha_{1}, \alpha_{2}, \beta_{1}$, and $\beta_{2}$ are functions of $T$ and $\Delta$ for the ground state and $T$ and $\Delta^{\prime}$ for the excited state, where $\Delta^{\prime}=\Delta+U-Q$, with $U$ the $3 \mathrm{~d}-3 \mathrm{~d}$ electron repulsion and $Q$ the $2 \mathrm{p}-3 \mathrm{~d}$ repulsion. Ligand field, $T$, and $\Delta$ were allowed to vary in the final state fits (i.e., decrease) but had little effect on the covalent mixing observed from the fits. Simulations showing the effects of varying final state $T, \Delta$, and ligand field parameters are given in Figure S9 (Supporting Information). In order to include back-bonding (MLCT) in addition to $\sigma$-donation, it is necessary to introduce a third state, $\Delta_{\mathrm{p}}$, above the $\mathrm{d}^{N}$ configuration; the ground-state wave function is now a linear combination of three configurations, $3 \mathrm{~d}^{N-1} \mathrm{~L}^{-}, 3 \mathrm{~d}^{N}$, and $3 \mathrm{~d}^{N+1}$ L. Further technical details and program input files for the three configuration simulations, including both LMCT and MLCT, are given elsewhere..$^{50}$

\section{Computational Details}

To simulate the spectra, the effects of the different components of bonding were systematically evaluated. First, the effects of $\sigma$ - and $\pi$-donation were included by LMCT simulations; the addition of $\pi$ backbonding to the porphryin and other effects were then systematically considered by including MLCT. Parameters that determine the energy separation in the ground state between the $\mathrm{d}^{N-1} \mathrm{~L}^{-}, \mathrm{d}^{N}$, and $\mathrm{d}^{N+1} \underline{\mathrm{L}}$ configurations ( $\Delta$ and $\Delta_{\mathrm{p}}$ ) were calculated from the program parameters $(\mathrm{EG} 1 / \mathrm{EG} 2 / \mathrm{EG} 3),{ }^{69}$ and those in the final state $\left(\Delta^{\prime}\right.$ and $\left.\Delta_{\pi}{ }^{\prime}\right)(\mathrm{EF} 1 / \mathrm{EF} 2 /$ EF3) were initially chosen on the basis of previous results ${ }^{50}$ and then systematically varied to optimize the spectral fit.

In order to get the DOC, the projection method of ref 48 was applied. This method uses the TT-multiplets program to split the intensity of the spectrum into its different symmetry components via dummy transitions $(4 s \rightarrow 4 p)$. These values are then degeneracy weighted to get the DOC.

DFT Calculations. The starting structures of the two molecular complexes, $\left[\mathrm{Fe}(\mathrm{tpp})(\operatorname{ImH})_{2}\right]^{+}$and $\left[\mathrm{Fe}(\mathrm{tpp})(\operatorname{ImH})_{2}\right]$, were taken from the crystal structure of $\left[\mathrm{Fe}(\mathrm{tpp})(\mathrm{ImH})_{2}\right](\mathrm{Cl}) \cdot\left(\mathrm{H}_{2} \mathrm{O}\right) \cdot\left(\mathrm{CHCl}_{3}\right){ }^{61}$ Those of $\left[\mathrm{Fe}(\operatorname{tacn})_{2}\right]^{3+/ 2+}$ were taken from the $\left[\mathrm{Fe}(\operatorname{tacn})_{2}\right] \mathrm{Cl}_{3} \cdot 5 \mathrm{H}_{2} \mathrm{O}^{70,71}$ and $[\mathrm{Fe}-$ $\left.(\operatorname{tacn})_{2}\right] \mathrm{Cl}_{2} \cdot 4 \mathrm{H}_{2} \mathrm{O}$ structures. ${ }^{72} \mathrm{In}$ all cases, the molecular structures of the Fe complexes were well isolated in the unit cell. DFT calculations

(67) Bianconi, A.; Della Longa, S.; Li, C.; Pompa, M.; Congui-Castelllano, A.; Udron, D.; Flank, A.-M.; Lagarde, P. Phys. Rev. B 1991, 44, 10126-10138.

(68) Ballhausen, C. J. Introduction to Ligand Field Theory; McGraw-Hill: New York, 1962.

(69) If the parameter EG1 is set to 0.0, the EG2 gives the energy separation between the lowest energy states of the $\mathrm{d}^{N-1}$ and $\mathrm{d}^{N}$ configurations, and EG3 gives the energy separation between the $\mathrm{d}^{N-1}$ and $\mathrm{d}^{N+1}$ configurations. (70) Marsh, R. E. Acta Crystallogr. B 1987, 43, 174-175.

(71) Wieghardt, K.; Schmidt, W.; Herrmann, W.; Kuppers, H.-J. Inorg. Chem. 1983, 22, 2953-2956. 
(ground state) were performed using the ADF program. ${ }^{73}$ The geometries were optimized using the exchange functional of Becke ${ }^{74}$ and the correlation functional of Perdew (BP86), as implemented in ADF. ${ }^{75}$ The frozen core approximation ${ }^{76}$ was used for the iron $1 \mathrm{~s}-2 \mathrm{p}$-orbitals. For valence orbitals, Slater-type orbital (STO) basis sets of triple- $\xi$ quality were employed with polarization functions on the ligand atoms (3d) and additional valence p-orbitals on the metal atoms (i.e., ADF basis set IV) ${ }^{73,77}$ This basis set combination has been shown to give a well-converged solution. ${ }^{78,79}$ Calculations were also performed including implicit solvation; this was done using the conductor-like screening model (COSMO) ${ }^{80-82}$ Nonbonded radii used (in $\AA$ ) were $\mathrm{N}=1.608$, $\mathrm{H}=1.350, \mathrm{C}=1.700, \mathrm{O}=1.517$, and $\mathrm{Fe}=1.80$. A dielectric constant of 78.8 (water) and an outer cavity radius of $1.9 \AA$ were further used to parametrize the COSMO solvation cavity. ${ }^{73,83}$ Solvation model orbital splitting patterns and mixing coefficients were found to be similar to those calculated using a gas-phase model. Ground-state energies and eigenfunctions (Kohn-Sham orbitals) were used to correlate to data. Previous studies on molecular systems have shown reasonable empirical correlations between experimental $\mathrm{d}-\mathrm{d}$ transitions and ground-state d-orbital energy differences,${ }^{84-86}$ which also correlated to TD-DFT calculation results ${ }^{86}$ Core hole effects on ligand field splittings using a cobalt atom with a nuclear charge of $\mathrm{Fe}$ have been evaluated elsewhere, ${ }^{87,88}$ trends in ligand field effects between compounds were found to be largely unaffected by the presence of the core hole. Mulliken population analysis was performed as implemented in ADF. ${ }^{89}$ Orbital plots were generated using G-OpenMol version 2.2. ${ }^{90}$

\section{Results}

Spectroscopy. A. Fe(II). Figure 1a shows the normalized Fe L-edge spectrum of $\left[\mathrm{Fe}(\mathrm{tpp})(\mathrm{ImH})_{2}\right]$ compared to that of $[\mathrm{Fe}-$ $\left.(\operatorname{tacn})_{2}\right] \mathrm{Cl}_{2}$ (taken from ref 48). The Fe L-edge spectrum of [Fe$\left.(\operatorname{tpp})(\operatorname{ImH})_{2}\right]$ increases slightly in total intensity and shifts 0.7 $\mathrm{eV}$ to higher energy relative to that of the non-heme low-spin $\mathrm{Fe}^{\mathrm{II}}$ reference complex. The change in intensity corresponds to a change in the total metal d character in the unoccupied orbitals, which goes from $295 \pm 20$ (non-heme) to $309 \pm 30 \%$ (heme) (Table 1). ${ }^{91}$ In systems without back-bonding, higher $\mathrm{d}$ character in unoccupied orbitals indicates lower covalency, where covalency is defined as the amount of ligand character in the metal

(72) Boeyens, J. C. A.; Forbes, A. G. S.; Hancock, R. D.; Wieghardt, K. Inorg. Chem. 1985, 24, 2926-2931.

(73) Baerends, E. J.; et al. Amsterdam Density Functional, version 01; Vrije Universiteit: Amsterdam, 2000.

(74) Becke, A. D. Phys. Rev. A 1988, 38, 3098-3100.

(75) Perdew, J. P. Phys. Rev. B 1986, 33, 8822-8824.

(76) Baerends, E. J.; Ellis, D. E.; Ros, P. Theor. Chim. Acta 1972, 27, 339354.

(77) Te Velde, G.; Baerends, E. J.; Fonseca, G. C.; Van Gisbergen, S. J. A.; Snijders, J. G.; Ziegler, T. J. Comput. Chem. 2001, 22, 931-967.

(78) Ryde, U.; Olsson, M. H. M.; Pierloot, K. In Theoretical BiochemistryProcesses and Properties of Biological Systems (Theoretical and Computational Chemistry); Eriksson, L. A., Ed.; Elsevier Science B.V.: Amsterdam, 2001; Vol. 9 (Theoretical Biochemistry), pp 1-55.

(79) Siegbahn, P. E. M.; Blomberg, M. R. A. Chem. Rev. 2000, 100, 421-437.

(80) Klamt, A. J. Chem. Phys. 1995, 99, 2224.

(81) Klamt, A.; Jones, V. J. Chem. Phys. 1996, 105, 9972.

(82) Klamt A.; Schuurmann, G. J. Chem. Soc., Perkin Trans. 2 1993, 799.

(83) Versluis, L.; Ziegler, T. J. Chem. Phys. 1988, 88, 322.

(84) Solomon, E. I.; Szilagyi, R. K.; Debeer George, S.; Basumallick, L. Chem. Rev. 2004, 104, 419-458.

(85) Basumallick, L.; Sarangi, R.; Debeer George S.; Elmore, B.; Hooper, A. B.; Hedman, B.; Hodgson, K. O.; Solomon, E. I. J. Am. Chem. Soc. 2005, 127, 3531-3544.

(86) Gorelsky, S. I.; Basumallick, L.; Vura-Weis, J.; Sarangi, R.; Hodgson, K. O.; Hedman, B.; Fujisawa, K.; Solomon, E. I. Inorg. Chem. 2005, 44, 4947-4960.

(87) Westre, T. E.; Kennepohl, P.; DeWitt, J. G.; Hedman, B.; Hodgson, K. O.; Solomon, E. I. J. Am. Chem. Soc. 1997, 119, 6297-6314.

(88) Dey, A.; Hocking, R. K.; Larsen, P.; Borovik, A. S.; Hodgson, K. O.; Hedman, B.; Solomon, E. I. J. Am. Chem. Soc. 2006, 128, 9825-9833.

(89) Mulliken, R. S. J. Chem. Phys. 1955, 23, 1833-1840.

(90) http://www.csc.fi/gopenmol/distribute/index.phtml.

(91) An L-edge arises from a $2 \mathrm{p} \rightarrow 3 \mathrm{~d}$ transition which is electric dipole allowed Thus, intensity is proportional to the total d-character in unoccupied orbitals.
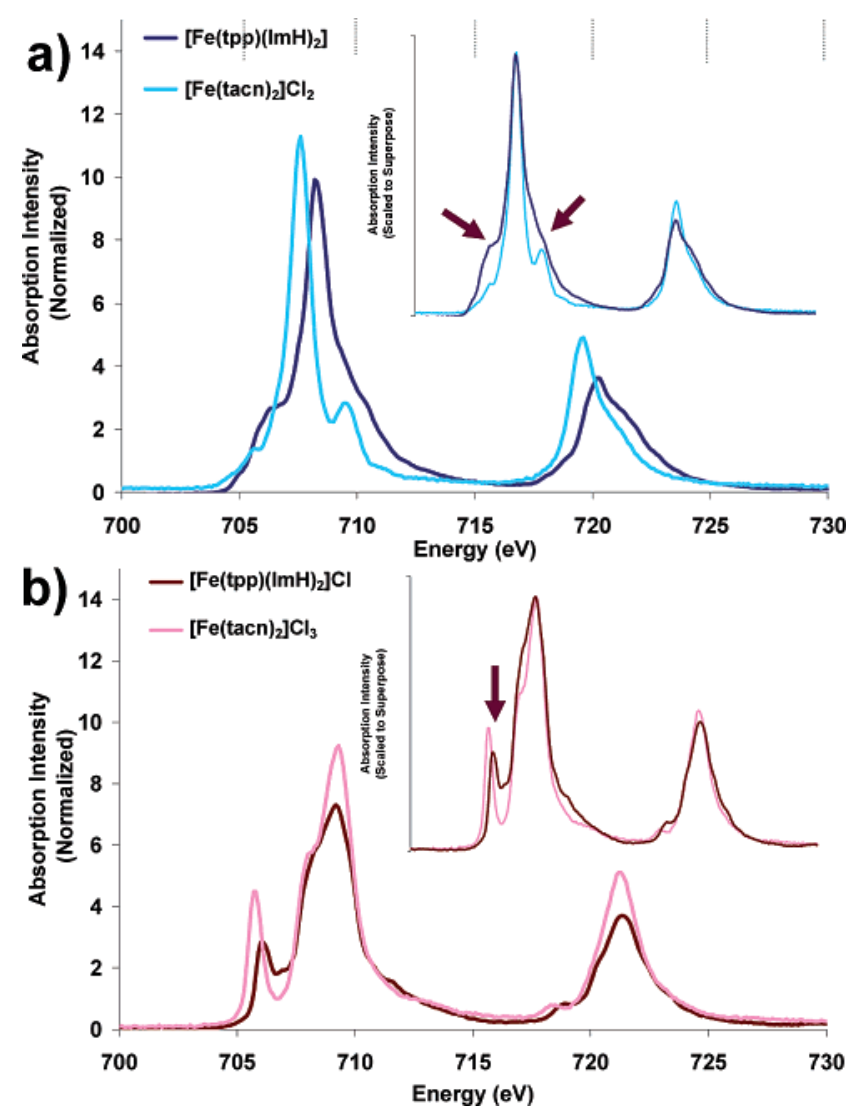

Figure 1. Fe L-edge comparison of heme and non-heme Fe compounds: (a) $\left[\mathrm{Fe}(\mathrm{tacn})_{2}\right] \mathrm{Cl}_{2}$ and $\left[\mathrm{Fe}(\mathrm{tpp})(\mathrm{ImH})_{2}\right]$; (b) $\left[\mathrm{Fe}(\mathrm{tacn})_{2}\right] \mathrm{Cl}_{3}$ and $[\mathrm{Fe}(\mathrm{tpp})-$ $\left.(\mathrm{ImH})_{2}\right] \mathrm{Cl}$. Insets show spectra that have been intensity-scaled and energyshifted to superimpose.

d-orbitals. In systems where back-bonding is present, there is also a covalency contribution arising from the mixing of occupied metal character into the unoccupied ligand orbitals, which increases total intensity. When the spectra are scaled and superimposed (Figure 1a, inset), we see an increase in intensity on both sides of the main multiplet packet, indicated by the arrows in Figure 1.

B. Fe(III). Figure $1 \mathrm{~b}$ shows the normalized Fe L-edge spectrum of $\left[\mathrm{Fe}(\mathrm{tpp})(\mathrm{ImH})_{2}\right] \mathrm{Cl}$ compared to that of $\left[\mathrm{Fe}(\operatorname{tacn})_{2}\right]$ $\mathrm{Cl}_{3}$ (from ref 48). The $\mathrm{Fe}$ L-edge spectrum of the heme compound $\left[\mathrm{Fe}(\mathrm{tpp})(\mathrm{ImH})_{2}\right]$ decreases in total intensity and shifts slightly $(0.1 \mathrm{eV})$ to lower energy relative to that of the lowspin non-heme reference complex. The decrease in total intensity corresponds to a change in the valence metal character from $351 \pm 25$ to $303 \pm 27 \%$ (Table 1 ). The decrease in metal character of the low-spin $\mathrm{Fe}$ (III) heme relative to the non-heme reference complex has two possible contributions: an increase in net ligand donation and/or a decrease in back-bonding. This decrease in intensity is opposite to the small increase observed in the $\mathrm{Fe}$ (II) L-edges described above. When the spectra of [Fe$\left.(\operatorname{tacn})_{2}\right] \mathrm{Cl}_{3}$ and $\left[\mathrm{Fe}(\mathrm{tpp})(\mathrm{ImH})_{2}\right]$ are scaled and superimposed (Figure 1b, inset), the feature to lowest energy (assigned as a $2 \mathrm{p}$ transition to the $\left(t_{2 g}\right)^{5} O_{h}$ hole $)^{48}$ shifts closer in energy to the main feature and significantly decreases in intensity.

DFT Calculations. The DFT calculations described here compare the bonding between heme and non-heme Fe systems, where the non-heme system chosen for comparison is ironcomplexed to two 1,4,7-triazacyclononane (tacn) ligands, as shown in Chart 1 . Tacn is a tridentate secondary amine chelate 
Table 1. Summary of Fe L-Edge Experimental Data for $\left[\mathrm{Fe}(\mathrm{tpp})(\mathrm{ImH})_{2}\right] \mathrm{Cl}$, $\left[\mathrm{Fe}(\operatorname{tacn})_{2}\right] \mathrm{Cl}_{3},\left[\mathrm{Fe}(\mathrm{tpp})(\mathrm{ImH})_{2}\right]$, and $\left[\mathrm{Fe}\left(\operatorname{tacn}_{2}\right)\right] \mathrm{Cl}_{2}$

\begin{tabular}{|c|c|c|c|c|c|c|c|c|}
\hline & $\begin{array}{c}\text { total } \\
\text { intensity }\end{array}$ & $\begin{array}{l}\% \text { metal character, } \\
\text { summed over } \\
\text { unoccupied orbitals }\end{array}$ & $\begin{array}{l}\% \text { average metal } \\
\text { character in } \\
\text { unoccupied orbitals }{ }^{a}\end{array}$ & $\begin{array}{c}\mathrm{L}_{3} \\
\text { area }\end{array}$ & $\begin{array}{l}\mathrm{L}_{2} \\
\text { area }\end{array}$ & $\begin{array}{l}\text { branching } \\
\quad \text { ratio } \\
\mathrm{L}_{3}\left(\mathrm{~L}_{2}+\mathrm{L}_{3}\right)\end{array}$ & $\begin{array}{c}\mathrm{L}_{3} \text { intensity-weighted } \\
\text { edge energy center } \\
(\mathrm{eV})\end{array}$ & $\begin{array}{c}\mathrm{L}_{2} \text { intensity-weighted } \\
\text { edge energy center } \\
(\mathrm{eV})\end{array}$ \\
\hline $\begin{array}{l}{\left[\mathrm{Fe}(\operatorname{tacn})_{2}\right] \mathrm{Cl}_{3},} \\
\mathrm{Fe}^{\mathrm{III}} \text { non-heme }{ }^{48}\end{array}$ & $43.8(3.5)$ & $351(25)$ & $\begin{array}{l}70(5) \\
\text { as Fe(III) }\end{array}$ & 29.6 & 15.9 & 0.67 & 709.0 & 721.4 \\
\hline $\begin{array}{l}{\left[\mathrm{Fe}(\mathrm{tpp})(\mathrm{ImH})_{2}\right] \mathrm{Cl}} \\
\mathrm{Fe}^{\mathrm{III}} \text { heme }\end{array}$ & $38.3(2.5)$ & $303(27)$ & $\begin{array}{l}61(6) \\
\text { as } \mathrm{Fe}(\mathrm{III})\end{array}$ & 26.3 & 12.0 & 0.69 & 708.9 & 721.3 \\
\hline $\begin{array}{l}{\left[\mathrm{Fe}(\operatorname{tacn})_{2}\right] \mathrm{Cl}_{2},} \\
\quad \mathrm{Fe}^{\mathrm{II}} \text { non-heme }\end{array}$ & $37.4(2.5)$ & $295(20)$ & $\begin{array}{l}74(5) \\
\text { as } \mathrm{Fe}(\mathrm{II})\end{array}$ & 23.7 & 13.7 & 0.65 & 707.6 & 720.0 \\
\hline $\begin{array}{l}{\left[\mathrm{Fe}(\mathrm{tpp})(\operatorname{ImH})_{2}\right]} \\
\mathrm{Fe}^{\mathrm{II}} \text { heme }\end{array}$ & $39(3.5)$ & $309(30)$ & $\begin{array}{l}77(7) \\
\text { as Fe(II) }\end{array}$ & 26.6 & 12.4 & 0.68 & 708.4 & 720.6 \\
\hline
\end{tabular}

${ }^{a}$ The $\%$ metal character summed over unoccupied orbitals reflects the combined effects of covalency and back-bonding. In a system with no backbonding, this number divided by the number of holes gives the $\%$ metal character in each orbital. For example, for $\left[\mathrm{Fe}(\mathrm{tacn})_{2}\right] \mathrm{Cl} \mathrm{H}_{3}, 351 / 5=70$, as given in column 3 , row 1 .

\section{Chart 1}

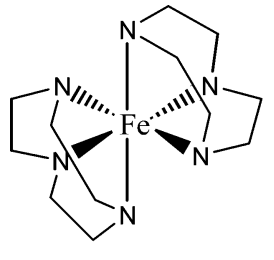

$\left[\mathrm{Fe}(\operatorname{tacn})_{2}\right]^{2+/ 3+}$

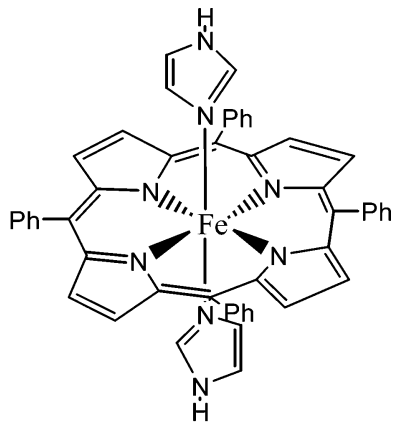

$\left[\mathrm{Fe}(\mathrm{tpp})(\operatorname{ImH})_{2}\right]^{0+/ 1+}$ that interacts with a metal as a $\sigma$-donor set with approximately $O_{h}$ symmetry. In an $O_{h}$ ligand field, the Fe d-orbitals split into the two-fold-degenerate $e_{g} \sigma^{*}$ set and the three-fold-degenerate $t_{2 g} \pi_{\mathrm{nb}}$ set. $\left[\mathrm{Fe}(\operatorname{tacn})_{2}\right]^{2+/ 3+}$ has a trigonal distortion which further splits the metal $t_{2 g}$-orbitals into $e_{g}\left(D_{3 d}\right)$ and $a_{1 g}\left(D_{3 \mathrm{~d}}\right)$ sets. The actual $\mathrm{Fe}$ site symmetry in the crystal is $C_{1},{ }^{71,92}$ and the molecular orbital (MO) calculations on $\left[\mathrm{Fe}(\operatorname{tacn})_{2}\right]^{2+/ 3+}$ compounds were performed in $C_{1}$ symmetry.

The heme ligand set studied here is comprised of the tetraphenylporphyrin (tpp) and two axial imidazoles ( $\operatorname{ImH})$. The effective symmetry of the heme complex, excluding the axial imidazoles and phenyl substituents, is $D_{4 h}$. Under $D_{4 h}$ symmetry, the heme ligand has two occupied orbitals capable of engaging in $\sigma$-donor interactions with the $\mathrm{Fe}(3 \mathrm{~d})$ orbitals, one with $\mathrm{b}_{1 \mathrm{~g}}$ $\left(D_{4 h}\right)$ symmetry, which will interact with the metal $\mathrm{d}_{x^{2}}-y^{2}$-orbital, and an orbital of $a_{1 g}\left(D_{4 h}\right)$ symmetry, which can interact with the metal $\mathrm{d}_{z^{2}}$-orbital. There are two additional sets of porphyrin orbitals which have a $\pi$ interaction with the metal. The $3 e_{g}$ $\left(D_{4 h}\right)$ porphyrin orbitals are occupied and act as $\pi$-donors, while the $4 e_{g}\left(D_{4 h}\right)$ porphyrin orbitals are unoccupied and capable of acting as $\pi$-acceptors. A MO diagram for two axial imidazoles oriented in an eclipsed configuration is given in Figure S2 (Supporting Information). A MO diagram for tpp (in $C_{i}$ symmetry) is given in Figure S3 (Supporting Information). In this configuration, orbital 12 of the axial $\mathrm{ImH}$ can act as a $\sigma$-donor, orbitals 11 and 13 can act as $\pi$-donors, and orbital 14 (LUMO) can act as a $\pi$-acceptor. When combined with a metal, this axial ligation produces a complex with $C_{i}$ symmetry.

A. Fe(II). Figure 2 shows the energy levels from spinrestricted calculations of $\left[\mathrm{Fe}(\mathrm{tpp})(\mathrm{ImH})_{2}\right](\mathrm{left})$ and $\left[\mathrm{Fe}(\operatorname{tacn})_{2}\right]^{2+}$ (right). Spin-unrestricted calculations were also performed and converged to the same solutions. The decomposition of the orbitals into their respective fragments from Mulliken population analyses is given in Table 2 and Figure 2. The predominantly metal-based orbitals are offset to the center, and the predominantly ligand-based $\pi^{*}$-orbitals are offset to the side.

When tacn interacts with $\mathrm{Fe}(\mathrm{II})$, the three orbitals to lower energy (orbitals 59-61), approximating the $t_{2 g}$ set in $O_{h}$ symmetry, have mostly metal character (93\%), and the two orbitals to higher energy (orbitals 63 and 62), which are approximately the $e_{g}\left(O_{h}\right)$ set split by the low-symmetry ligand field, have decreased metal character $(71 \%)$. Thus, the tacn ligands form $\sigma$-donor bonding interactions with the metal but, as expected, do not have any substantial $\pi$ interaction.

In the heme system, the five Fe d-orbitals split with two orbitals to higher energy (orbitals 81 and 76), the $e_{g}$ set in $O_{h}$, and three to lower energy (orbitals 71-73), the $t_{2 g}\left(O_{h}\right)$ set

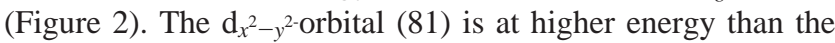
$\mathrm{d}_{z^{2}}$-orbital (76) by about $1 \mathrm{eV}$, which indicates that the porphyrin is a better $\sigma$-donor than the ImH's because $\mathrm{d}_{z^{2}}$ has contributions from both the porphyrin $a_{1 g}\left(D_{4 h}\right)$ and the ImH-12. Both the

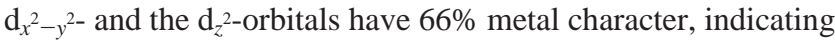
that the heme ligand set is a stronger $\sigma$-donor than the tacn ligand.

In low-spin Fe(II), the metal-based $t_{2 g}$ (in $O_{h}$ ) orbitals 72, 71 , and 73 are occupied; thus, their mixing with occupied ligand orbitals does not contribute any net bonding. However, the effects of back-bonding are evident (Figure 2) from both the metal character in the unoccupied porphyrin-based $4 e_{g}\left(D_{4 h}\right)$ orbitals $(9 \%, 74$ and 75$)$ and the porphyrin $4 e_{g}\left(D_{4 h}\right)$ character (from a fragment analysis in ADF) mixed into the metal-based

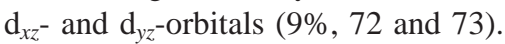

B. Fe(III). Figure 3 shows the $\beta$-spin molecular orbitals from the spin-unrestricted DFT calculations for $\left[\mathrm{Fe}(\mathrm{tpp})(\mathrm{ImH})_{2}\right]^{+}(\mathrm{left})$ and $\left[\mathrm{Fe}(\operatorname{tacn})_{2}\right]^{3+}$ (right). As for $\mathrm{Fe}$ (II), orbitals that are predominantly metal-based are offset to the center of the diagram, with the porphyrin $\pi^{*}$-orbitals to the side. A more complete MO diagram, including the $\sigma$ - and $\pi$-donor orbitals that interact with the metal, is given in the Supporting Information, Figure S5. The decomposition of the orbitals into their respective fragments using a Mulliken population analysis ${ }^{89}$ is given in Table 2 .

As is the case for the $\mathrm{Fe}(\mathrm{II})$ systems, the $\sigma$-donor interactions of the heme and non-heme ligand sets are calculated by DFT to be similar. The interaction with the porphyrin ligand results

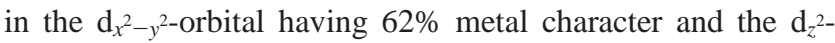
orbital having $68 \%$ metal character. In comparison, the nonheme tacn complex has $64 \%$ metal character for both orbitals. 


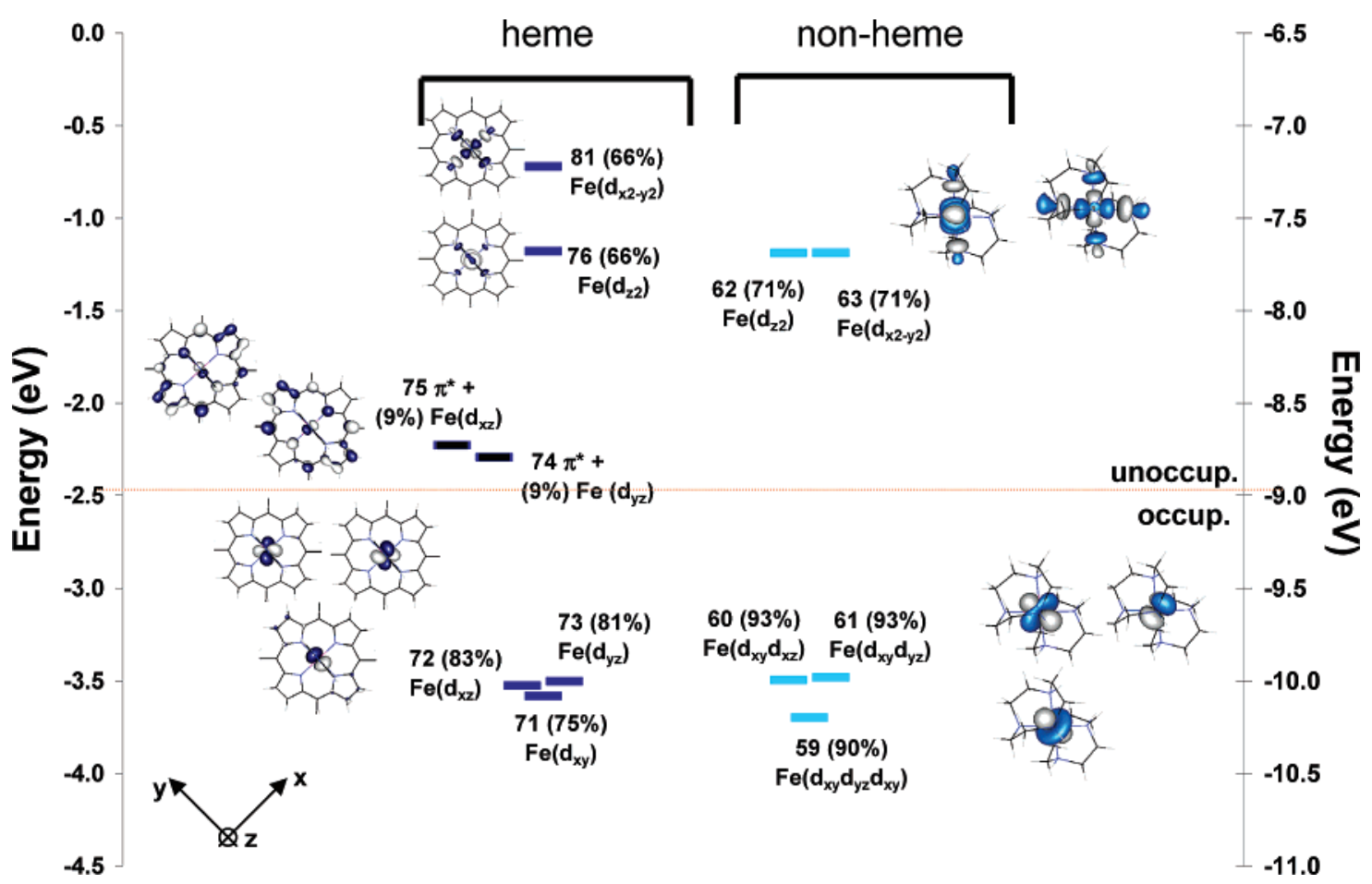

Figure 2. Comparison of energy levels for $\mathrm{Fe}(\mathrm{II})$ in a ferro-heme $\left[\mathrm{Fe}(\operatorname{tpp})(\mathrm{ImH})_{2}\right]$ and a non-heme $\left[\mathrm{Fe}(\operatorname{tacn})_{2}\right]^{2+}$ coordination. Orbitals are numbered as the output from ADF calculations, with the \% metal character in each orbital given in parentheses after the orbital number. Orbitals with metal character are fully colored. The predominantly porphyrin $\pi^{*}$-orbitals are colored in black. The main contributors to each $\mathrm{MO}$ of the compound $\left[\mathrm{Fe}(\mathrm{tpp})(\mathrm{ImH})_{2}\right]$ are given in Table 2 and in the Supporting Information, where plots including the main porphyrin and ImH bonding orbitals are given in Figures S2 and S3. ${ }^{94}$

Table 2. Key Orbital Components for the DFT Calculations of $\mathrm{Fe}(\mathrm{II})\left(\left[\mathrm{Fe}(\mathrm{tpp})(\mathrm{ImH})_{2}\right]\right)$ and $\mathrm{Fe}(\mathrm{III})\left(\left[\mathrm{Fe}(\operatorname{tpp})(\operatorname{ImH})_{2}\right]^{+}\right)^{a}$

\begin{tabular}{|c|c|c|}
\hline $\begin{array}{l}\text { main contribution } \\
\text { to MO }\end{array}$ & $\mathrm{Fe}(\mathrm{II})$ heme & $\mathrm{Fe}(\mathrm{III})$ heme \\
\hline $\mathrm{Fe}\left(\mathrm{d}_{x^{2}-y^{2}}\right)$ & 81. $67 \%\left(\mathrm{Fe}-\mathrm{d}_{x^{2}-y^{2}}\right)+27 \%\left(6 b_{2 g}\right.$-tpp $)+4 \%($ tpp-other $)$ & 77. $61 \%\left(\mathrm{Fe}-\mathrm{d}_{x^{2}-y^{2}}\right)+29 \%\left(\mathrm{tpp}-6 b_{2 g}\right)+6 \%\left(\mathrm{Fe}-\mathrm{d}_{z^{2}}\right)$ \\
\hline $\mathrm{Fe}\left(\mathrm{d}_{z^{2}}\right)$ & $\begin{array}{l}\text { 76. } 65 \%\left(\text { Fe- } \mathrm{d}_{z^{2}}\right)+9 \%\left(\text { tpp- } a_{1 g}\right)+2 \%(\text { tpp-other })+ \\
18 \%(\operatorname{ImH}-12)+6 \%(\text { ImH-other })\end{array}$ & $\begin{array}{l}\text { 76. } 59 \%\left(\mathrm{Fe}-\mathrm{d}_{z^{2}}\right)+20 \%(\mathrm{ImH}-12)+8 \%\left(\mathrm{tpp}-a_{1 g}\right)+ \\
5 \%\left(\mathrm{Fe}-\mathrm{d}_{x^{2}-y^{2}}\right)\end{array}$ \\
\hline $\begin{array}{c}\text { heme } \pi \text {-acceptor } \\
\left(4 e_{g}\left(D_{4 h}\right)\right)\end{array}$ & 75. $90 \%\left(\right.$ tpp- $\left.4 e_{g}\right)+9 \% \mathrm{Fe}\left(\mathrm{d}_{y z} / \mathrm{d}_{x z}\right)$ & 75. $94 \%\left(\mathrm{tpp}-4 e_{g}\right)+6 \%\left(\mathrm{Fe}-\mathrm{d}_{y z}\right)$ \\
\hline & & 74. $95 \%\left(\operatorname{tpp}-4 e_{g}\right)+* 3 \%\left(\mathrm{Fe}-\mathrm{d}_{x z}\right)$ \\
\hline \multirow[t]{2}{*}{$\operatorname{Fe}\left(\mathrm{d}_{x z} / \mathrm{d}_{y z}\right)$} & $\begin{array}{l}\text { 73. } 81 \%\left(\text { Fe- } \mathrm{d}_{x y}+\mathrm{d}_{x z}\right)+6 \%\left(\text { tpp- } 4 e_{g}\right)+2 \%(\text { ImH-other })+ \\
5 \%(\text { tpp-other })\end{array}$ & $\begin{array}{l}\text { 73. } 70 \%\left(\mathrm{Fe}-\mathrm{d}_{y z}\right)+20 \%\left(\mathrm{tpp}-3 e_{g}\right)+2 \%\left(\mathrm{tpp}-4 e_{g}\right)+ \\
3 \%(\operatorname{ImH}-11)\end{array}$ \\
\hline & 72. $83 \%\left(\mathrm{Fe}-\mathrm{d}_{x y}+\mathrm{d}_{x z}\right)+7 \%\left(\mathrm{tpp}-4 e_{g}\right)+4 \%$ (tpp-other) & 72. $71 \%\left(\mathrm{Fe}-\mathrm{d}_{x z}\right)+22 \%\left(\mathrm{tpp}-3 e_{g}\right)+2 \%\left(\mathrm{tpp}-4 e_{g}\right)$ \\
\hline $\mathrm{Fe}\left(\mathrm{d}_{x y}\right)$ & 71. $75 \%\left(\mathrm{Fe}-\mathrm{d}_{y z}\right)+15 \%\left(\mathrm{tpp}-3 e_{g}\right)+6 \%\left(\mathrm{tpp}-4 e_{g}\right)+5 \%($ tpp-other $)$ & 71. $93 \% \mathrm{Fe}\left(\mathrm{d}_{x y}\right)$ \\
\hline $\begin{array}{l}\text { heme } \pi \text {-donor } \\
\qquad\left(3 e_{g}\left(D_{4 h}\right)\right)\end{array}$ & $\begin{array}{l}\text { 69. 56\%(tpp-3eg })+22 \%(\text { tpp-52Ag })+7 \%\left(\mathrm{Fe}-\mathrm{d}_{y z}\right)+ \\
11 \%(\text { tpp-other })+7 \%\left(\text { Fe- } \mathrm{d}_{x z} / \mathrm{d}_{y z} / \mathrm{d}_{x y}\right)\end{array}$ & 64. $71 \%\left(\operatorname{tpp}-3 e_{g}\right)+19 \%\left(\mathrm{Fe}-\mathrm{d}_{y z}\right)$ \\
\hline $\begin{array}{l}\text { heme } \sigma \text {-donor } \\
\qquad\left(6 \mathrm{~b}_{1 \mathrm{~g}}\left(D_{4 h}\right)\right)^{b}\end{array}$ & $\begin{array}{l}\text { 60. } 50 \%\left(\text { tpp- } 6 b_{2 g}\right)+22 \%\left(\mathrm{Fe}-\mathrm{d}_{x^{2}-y^{2}}\right)+12 \%(\text { tpp- } 41 \mathrm{Ag})+ \\
14 \%(\text { tpp-other })+3 \%(\text { ImH-other })\end{array}$ & $\begin{array}{l}\text { 55. } 36 \%\left(\text { tpp }-41 a_{g}\right)+34 \%\left(\text { tpp }-6 b_{2 g}\right)+15 \%\left(\text { Fe- } d_{x^{2}-y^{2}}\right)+ \\
\quad 7 \%(\text { tpp- } 45 \mathrm{Ag})\end{array}$ \\
\hline \multirow[t]{2}{*}{$\begin{array}{l}\text { heme } \sigma \text {-donor } \\
\qquad\left(7 a_{1 g}\left(D_{4 h}\right)\right)^{93}\end{array}$} & $\begin{array}{l}\text { 56. } 33 \%\left(\text { tpp- } 7 a_{1 g}\right)+22 \%\left(\text { tpp- } 42 a_{\mathrm{g}}\right)+18 \%\left(\mathrm{Fe}-\mathrm{d}_{z^{2}}\right)+ \\
18 \%\left(\operatorname{ImH}-12 a_{g}\right)+5 \%(\text { tpp-other })\end{array}$ & 52. $38 \%\left(\right.$ tpp- $\left.-7 a_{1 g}\right)+23 \%\left(\right.$ Fe- $\left.\mathrm{d}_{z^{2}}\right)+15 \%\left(\operatorname{ImH}-12 \mathrm{a}_{\mathrm{g}}\right)$ \\
\hline & & $\begin{array}{l}\text { 50. } 33 \%\left(\text { tpp- }-42 a_{g}\right)+16 \%\left(\text { tpp- }-40 a_{g}\right)+16 \%\left(\text { tpp }-6 b_{2 g}\right)+ \\
10 \%\left(\mathrm{Fe}-\mathrm{d}_{x^{2}-y^{2}}\right)+2 \%\left(\mathrm{Fe}-\mathrm{d}_{z^{2}}\right)\end{array}$ \\
\hline
\end{tabular}

${ }^{a}$ MO diagrams of tpp and $\mathrm{ImH}$ are given in the Supporting Information, Figures S2 and S3. Bold numbers indicate the orbital number from the ADF calculation. ${ }^{b}$ The $x$ and $y$ axes bisect the $\mathrm{N}-\mathrm{Fe}-\mathrm{N}$ bonds.

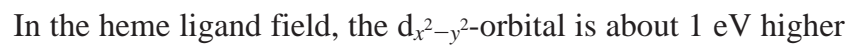
in energy than the $\mathrm{d}_{z^{2}}$-orbital, analogous to the $\mathrm{Fe}$ (II) heme calculation, which again indicates that the porphyrin is a stronger $\sigma$-donor than the axial ImH ligand.

For the Fe(III) system, the hole in the $t_{2 g}\left(O_{h}\right)$ d-orbital set allows for both the porphyrin and the axial $\mathrm{ImH}$ to potentially act as $\pi$-donors. When both $\mathrm{ImH}$ ligands are eclipsed and oriented along the $z$-axes with their molecular planes in the $x z$ plane, where $x$ is along an $\mathrm{Fe}-\mathrm{N}$ bond (Figure 3), this orientation allows their out-of-plane $\operatorname{ImH} \pi$-donor orbitals to interact with the $\mathrm{Fe} \mathrm{d}_{y z}$-orbital, destabilizing it to become the $\beta$-spin LUMO. This orbital (73) contains $20 \%$ porphyrin $\pi$-donor character $\left(3 e_{g}\right)$ and $3 \% \operatorname{ImH} \pi$-donor character (orbital 11), as recorded in Table 2. The contribution of $\mathrm{ImH}$ character to the LUMO orbital is relatively small; however, this interaction is sufficient to split the $\mathrm{Fe} \mathrm{d}_{x z} / \mathrm{d}_{y z}$-orbitals (72 and 73) in energy. Rotating the ImH planes out of the $x z$ plane and staggering these orientations changes the coefficients of mixing with the two porphyrin $3 e_{g}\left(D_{4 h}\right)$-orbitals (vide infra). ${ }^{30,41}$

The degree of $\pi$ back-bonding from Fe(III) to the porphyrin can be assessed from the coefficients of the occupied metal orbital $72\left(\mathrm{~d}_{x z}\right)$ and their relation to the unoccupied porphyrin $4 e_{g}\left(D_{4 h}\right)$-orbitals (since orbital $73\left(\mathrm{~d}_{y z}\right)$ is unoccupied, its interaction with the porphyrin $4 e_{g}$-orbital does not contribute 


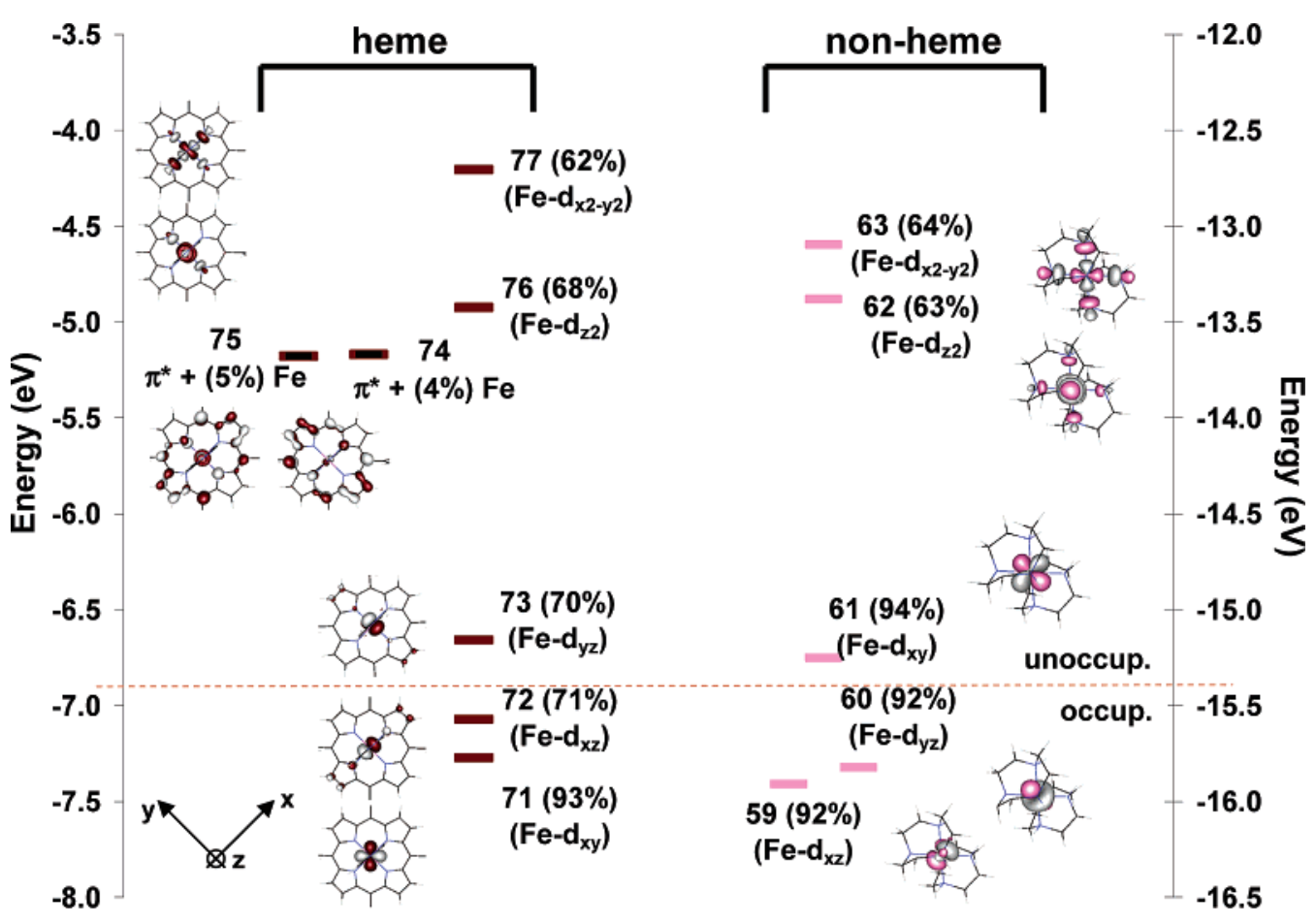

Figure 3. Comparison of the $\beta$-spin energy levels in $\mathrm{Fe}(\mathrm{III})$ heme vs non-heme: $\left[\mathrm{Fe}(\mathrm{tpp})(\mathrm{ImH})_{2}\right]^{+}$orbitals are colored red and $\left[\mathrm{Fe}(\operatorname{tacn})_{2}\right]^{3+}$ orbitals are colored pink. Orbitals are numbered as the output from ADF calculations, and the \% metal character is given in parentheses after the number for each orbital. Orbitals with predominant metal character are fully colored. Those which have predominantly porphyrin (tpp) character are colored in black. The main contributors to each of the MOs of the compound $\left[\mathrm{Fe}(\operatorname{tpp})(\mathrm{ImH})_{2}\right]$ are given in Table 2 and in the Supporting Information. ${ }^{94}$

to back-bonding). From Table 2, the metal character in the $4 e_{g}$ $\left(D_{4 h}\right) \pi$-acceptor porphyrin orbitals is seen to decrease upon going from $\mathrm{Fe}(\mathrm{II})(9 \%)$ to $\mathrm{Fe}(\mathrm{III})(2 \%)$, indicating that in the DFT calculations there is very little back-bonding in the Fe(III) heme complex. This is consistent with NMR results for low-spin $\mathrm{Fe}$ (III) porphyrinates, which show undetectably small contact shifts at the meso-carbons of $\left[\mathrm{PFeL}_{2}\right]^{+}$, where $\mathrm{L}=$ imidazoles and high-basicity pyridines. ${ }^{29,42}$

\section{Analysis}

1. L-Edge Intensity and Energy: Relative Contributions of $Z_{\text {eff }}$ and Ligand Field. Metal L-edge energy shifts are a consequence of three factors: the charge on the absorbing metal in the molecule $\left(Z_{\text {eff }}\right)$, ligand field splittings, and any difference in the nature of the transitions contributing to the spectra. ${ }^{50}$

In non-heme Fe systems, the ligand field contribution to the edge energy shifts can be estimated from optical 10Dq values. ${ }^{62}$ However, in heme systems, $10 \mathrm{Dq}$ values are not known because the $\pi \rightarrow \pi^{*}$ transitions obscure the metal $\mathrm{d}-\mathrm{d}$ absorption bands. ${ }^{95}$ From optical data, the $10 \mathrm{Dq}$ values for $\left[\mathrm{Fe}(\operatorname{tacn})_{2}\right]^{2+}$ and $[\mathrm{Fe}-$ $\left.(\operatorname{tacn})_{2}\right]^{3+}$ are 2.35 and $2.55 \mathrm{eV}$, respectively. ${ }^{71,92,96}$ These compare well with the values from ground-state DFT calculations of 2.37 and $2.45 \mathrm{eV}$. Thus, equivalent DFT calculations were used to estimate the d-orbital energy splittings in the heme complexes, giving for $\mathrm{Fe}(\mathrm{II}), 10 \mathrm{Dq}=2.86 \mathrm{eV}, \mathrm{Ds}=0.056$ $\mathrm{eV}$, and $\mathrm{Dt}=0.047 \mathrm{eV}$, and for Fe(III), $10 \mathrm{Dq}=2.45 \mathrm{eV}$, Ds

(92) Wieghardt, K.; Kuppers, H.-J.; Weiss, J. Inorg. Chem. 1985, 24, 30673071 .

(93) For both $\mathrm{Fe}(\mathrm{II})$ and $\mathrm{Fe}(\mathrm{III})$, the equivalent of the porphyrin $7 a_{1 g}$-orbital was distributed over many porphyrin-based orbitals

(94) The decomposition of the $\left[\mathrm{Fe}(\operatorname{tacn})_{2}\right] \mathrm{Cl}_{2} / \mathrm{Cl}_{3}$ orbitals is given in the Supporting Information.

(95) Makinen, M. W.; Churg, A. In Iron Porphyrins; Lever, A. B. P., Gray, H. B., Eds.; Addison-Wesley: Reading, MA,1983; Vol. 1, pp 141-235.
$=0.176 \mathrm{eV}$, and $\mathrm{Dt}=0.003 \mathrm{eV}$, where Ds and Dt are the ligand field parameters associated with the tetragonal distortion from $O_{h} \cdot{ }^{68}$

A. Fe(II). The effect of $Z_{\text {eff }}$ can be estimated from the total L-edge intensity, which reflects the total metal character in the unoccupied valence orbitals. In going from $\left[\mathrm{Fe}(\operatorname{tacn})_{2}\right]^{2+}$ to $[\mathrm{Fe}-$ $\left.(\operatorname{tpp})(\operatorname{ImH})_{2}\right]$, the total intensity does not change significantly (Table 1), indicating that the effect of $Z_{\text {eff }}$ on the energy shift is small. Ligand donation decreases intensity, whereas backbonding increases it. The small change in L-edge intensity indicates that heme $\sigma$-donation of the porphyrin is sufficiently large to counteract any contribution due to the back-bonding in the heme complex. On the basis of the DFT-calculated splittings of the d-orbitals, the L-edge spectrum of $\left[\mathrm{Fe}(\mathrm{tpp})(\mathrm{ImH})_{2}\right]$ should shift by $\sim 0.3 \mathrm{eV}$ to higher energy relative to that of $\left[\mathrm{Fe}(\operatorname{tacn})_{2}\right]$ $\mathrm{Cl}_{2} \cdot{ }^{97}$ The observed experimental shift in the Fe L-edge is 0.7 $\mathrm{eV}$. This difference could reflect an inadequate description by the ground-state DFT calculations or an additional multiplet edge energy shift to higher energy due to MLCT transitions associated with back-bonding. The VBCI analysis described below indicates that this effect is largely ligand field based.

B. Fe(III). On the basis of DFT calculations, the [Fe(tpp)$\left.(\operatorname{ImH})_{2}\right]^{+}$spectrum would shift $0.1 \mathrm{eV}$ to higher energy relative to that of $\left[\mathrm{Fe}(\operatorname{tacn})_{2}\right]^{2+}$. In comparing the L-edge spectra of [Fe$\left.(\operatorname{tacn})_{2}\right] \mathrm{Cl}_{3}$ and $\left[\mathrm{Fe}(\mathrm{tpp})(\mathrm{ImH})_{2}\right] \mathrm{Cl}$, a small decrease in total intensity is observed, indicating that $Z_{\mathrm{eff}}$ on the Fe atom has decreased, which would shift the spectrum to lower energy. The observed shift is close to zero, indicating that the ligand field counteracts the effect of $Z_{\mathrm{eff}}$.

(96) Ventor, D.; Wieghardt, K.; Nuber, B.; Weiss, J. Z. Z. Anorg. Allg. Chem. 1987, 551, 33-60.

(97) Ligand field differences are calculated by the covalency-weighted average of the unoccupied orbitals, as described in refs 48 and 50. 


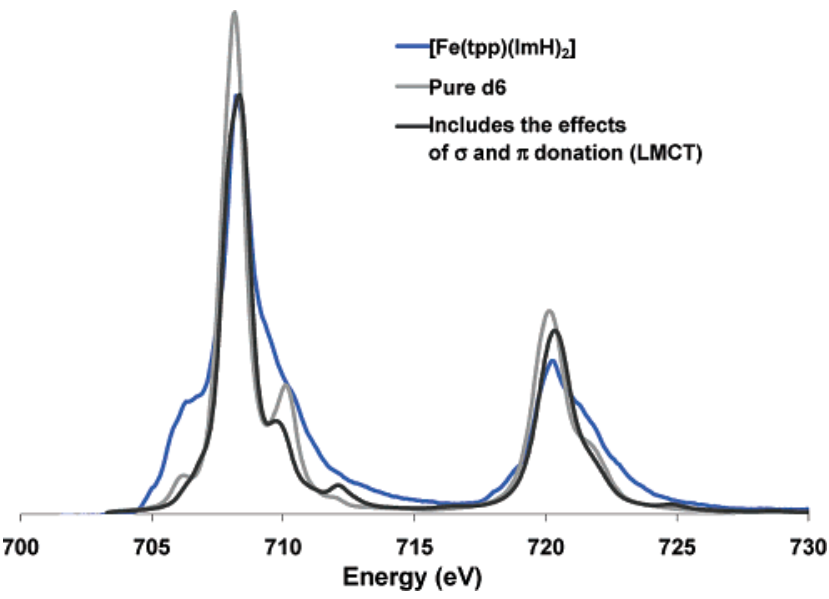

Figure 4. Fe L-edge spectrum of $\left[\mathrm{Fe}(\mathrm{tpp})(\mathrm{ImH})_{2}\right]$ (blue) compared to a calculated pure $\mathrm{d}^{6}$ ground state split by the DFT-calculated ligand field (light gray) and a simulation which includes the effects of ligand-to-metal charge transfer (dark gray).

2. VBCI Simulation of Fe(II) L-Edge Spectral Shape: Differential Orbital Covalency and Back-Bonding. VBCI simulations of the spectra of the low-spin Fe(II) complex were performed in $D_{4 h}$ symmetry. The simulations systematically included first $\sigma$ - and $\pi$-donation (ligand-to-metal charge transfer), second solely $\pi$ back-bonding (metal-to-ligand charge transfer), and finally all bonding contributions.

2.1. Multiplet Simulation: $\boldsymbol{\sigma}$ - and $\boldsymbol{\pi}$-Donation. Figure 4 shows three spectra: in blue, the experimental spectrum of [Fe$\left.(\operatorname{tpp})(\operatorname{ImH})_{2}\right]$; in light gray, the spectrum of a pure $\mathrm{d}^{6}$ ground state split by a ligand field $90 \%$ of that predicted from the DFT calculations described above (similar to the $\left[\mathrm{Fe}(\operatorname{tacn})_{2}\right] \mathrm{Cl}_{2}$ spectrum) $;{ }^{48}$ and in dark gray, a spectrum that shows the effects of adding $\sigma$ - and $\pi$-donation to the pale gray spectrum. It is clear from the figure that none of these simulations fits the data. The addition of $\sigma$ - and $\pi$-donation acts to sharpen the spectrum, not broaden it, as required to fit the experimental L-edge spectrum of the heme site.

2.2. Multiplet Simulation: Effect of $\boldsymbol{\pi}$ Back-Bonding on Spectral Shape. From our previous studies, the presence of a low-lying ligand $\pi^{*}$-orbital can have a significant effect on the shape of the Fe L-edge. ${ }^{50}$ This has been attributed to two mechanisms. First, occupied metal character is mixed into the unoccupied ligand $\pi^{*}$-orbital through back-bonding. Transitions to the metal character in these $\pi^{*}$-orbitals provide a new mechanism for gaining intensity. Second, a ground state having back-bonding (i.e., MLCT CI) is given by $\left|2 \mathrm{p}^{6} t_{2 g}{ }^{6}\right\rangle+$ $\left|2 \mathrm{p}^{6} t_{2 g}{ }^{5} \pi^{-}\right\rangle$. This produces L-edge excited states $\left|2 \mathrm{p}^{5} t_{2 g}{ }^{6} e_{g}{ }^{1}\right\rangle$ and $\left|2 \mathrm{p}^{5} t_{2 g}{ }^{5} e_{g}{ }^{1} \pi^{-}\right\rangle,{ }^{98}$ which can CI mix and thereby shift intensity from the $2 \mathrm{p} \rightarrow e_{g}$ transition to the $2 \mathrm{p} \rightarrow \pi^{*}$ transition packet. $^{50}$

Figure 5 shows a series of simulations (gray) which systematically include the different bonding interactions (the experimental spectrum is given in blue). Spectrum A is a pure Fe(II) low-spin ground state, which does not include $\sigma$ - or $\pi$-donation or $\pi$ back-bonding. Spectrum B includes only the effects of $\pi$ back-bonding, and spectrum $\mathrm{C}$ includes $\pi$ back-bonding and $\sigma$ - and $\pi$-donation. In adding $\pi$ back-bonding to a pure $\mathrm{d}^{6}$ lowspin ground state (Figure 5, A to B), the spectrum becomes broader and more consistent with the experimental spectrum.

(98) There is a third final configuration which does not mix: $\left|2 \mathrm{p}^{5} t_{2 g}{ }^{6}\right\rangle$.

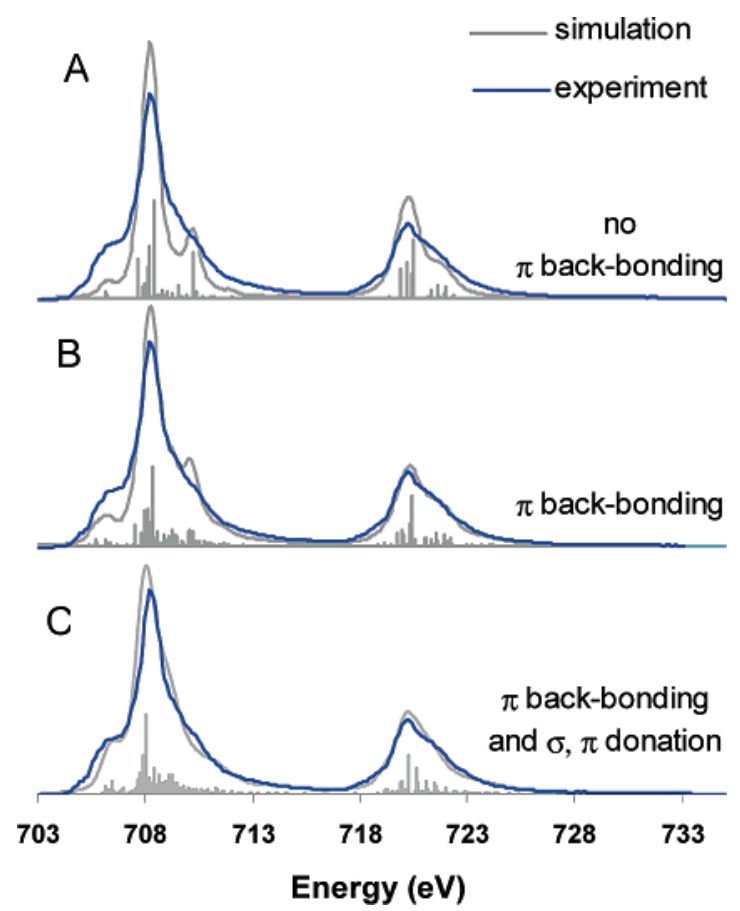

Figure 5. Effect of systematically adding $\pi$ back-bonding and $\sigma$ - and $\pi$-donation to a $\mathrm{d}^{6}$ ground state. The gray simulated curves in each case integrate to the same intensity, and the lines below each spectrum represent the individual transitions contributing to the spectrum.

The VBCI spectral simulations can be interpreted in terms of DOC, by the projection method described previously. ${ }^{48}$ Simulation $\mathrm{B}$ gives $9 \%$ back-bonding from the $\mathrm{Fe} \mathrm{d}_{x z} / \mathrm{d}_{y z}$-orbitals into the porphyrin $\pi^{*}$-orbitals but includes no donor bonding. When donor bonding effects are also included (mostly $\sigma$, simulation C), the simulation changes slightly, but the covalency values obtained are very similar. The final simulation gives $67 \%$ metal character in $\mathrm{d}_{x^{2}-y^{2}}, 65 \%$ metal character in $\mathrm{d}_{z^{2}}$, and $11 \%$ metal character in the porphyrin $\pi^{*}$-orbital. If the back-bonding is increased, either the simulated spectrum is too broad or an additional peak appears, which is inconsistent with the experimental spectrum (Figure S4B,C).

2.3. Comparison to DFT Calculations. From the VBCI simulations scaled to total intensity, ${ }^{99}$ the amount of metal character mixed into the unoccupied porphyrin $4 e_{g} \pi^{*}$-orbitals is around $11 \%$ for the Fe(II) complex. This amount of backbonding is consistent with the DFT calculations, which give $9 \%$ in the $\mathrm{d}_{x z} / \mathrm{d}_{y z}$-orbitals. From experiment, the $\%$ metal character in the $\mathrm{d}_{x^{2}-y^{2}-}$ and $\mathrm{d}_{z^{2}}$-orbitals is $65 \%$ and $67 \%$, respectively; the DFT calculations give $66 \%$ for both.

3. VBCI Simulations of the Fe(III) L-Edge. 3.1. Multiplet Simulation: Effects of $\boldsymbol{\sigma}$ - and $\boldsymbol{\pi}$-Donation. As for $\mathrm{Fe}(\mathrm{II})$, the VBCI simulations of the Fe(III) spectrum of [Fe(tpp)(ImH) 2$]-$ $\mathrm{Cl}$ were performed in $D_{4 h}$ symmetry ${ }^{100}$ and required LMCT CI mixing, i.e., a d $\mathrm{d}^{5}+\mathrm{d}^{6} \underline{\mathrm{L}}$ ground state. The parameters $T_{i}$ and $\Delta$ were varied to fit the data, starting from the parameters used to fit the non-heme spectrum of $\left[\mathrm{Fe}(\operatorname{tacn})_{2}\right] \mathrm{Cl}_{3}{ }^{48}$ (Table 4$)$, shown in gray for comparison in Figure 6A. To simulate the main spectral change in going to a heme complex, it was necessary to increase the $\pi$-donor interaction of the heme ligand. The effect of this is shown by the differences in simulations A and B in

(99) VBCI similations are scaled to the total orbital covalency.

(100) van der Laan, G.; Thole, B. T.; Sawatzky, G. A. Phys. Rev. B 1987, 37, $6587-6589$. 
Table 3. Comparison of Calculated and Experimental Covalency Values for $\left[\mathrm{Fe}(\operatorname{tpp})(\operatorname{ImH})_{2}\right]^{+},\left[\mathrm{Fe}(\operatorname{tacn})_{2}\right]^{3+},\left[\mathrm{Fe}(\mathrm{tpp})(\operatorname{ImH})_{2}\right]$, and $\left[\mathrm{Fe}\left(\operatorname{tacn}_{2}\right)\right]^{2+}$

\begin{tabular}{|c|c|c|c|c|c|c|c|c|}
\hline & \multirow[b]{2}{*}{$\begin{array}{c}\text { total } \\
\text { intensity }\end{array}$} & \multicolumn{2}{|c|}{$\begin{array}{l}\% \text { total metal character } \\
\text { in unoccupied orbitals }\end{array}$} & \multicolumn{5}{|c|}{$\begin{array}{l}\text { comparison of VBCl and DFT values for differential orbital covalency: } \\
\qquad \mathrm{VBCl}(\mathrm{DFT}), \%\end{array}$} \\
\hline & & $\begin{array}{l}\text { based on } \\
\text { intensity }\end{array}$ & $\begin{array}{l}\text { based on } \\
\text { DFT }\end{array}$ & $\begin{array}{c}\mathrm{B} 1 \\
\left(x^{2}-y^{2}\right)\end{array}$ & $\begin{array}{l}\mathrm{A} 1 \\
\left(z^{2}\right)\end{array}$ & $\begin{array}{l}\mathrm{B} 2 \\
(x y)\end{array}$ & $\begin{array}{c}E 1^{b} \\
(x z, y z)\end{array}$ & $\begin{array}{c}\pi^{*} \\
(x z, y z)\end{array}$ \\
\hline$\left[\mathrm{Fe}(\operatorname{tacn})_{2}\right] \mathrm{Cl}_{3}$ & 43.8 & 351 & 333 & $63(64)$ & $63(64)$ & $99(93)$ & $99(93)$ & \\
\hline$\left[\mathrm{Fe}(\operatorname{tacn})_{2}\right] \mathrm{Cl}_{2}$ & 37.4 & 295 & 284 & $74(72)$ & $74(72)$ & (93) & (93) & \\
\hline $\begin{array}{l}\text { A. }\left[\mathrm{Fe}(\mathrm{tpp})(\operatorname{ImH})_{2}\right] \\
\quad \mathrm{Fe}(\mathrm{II})\end{array}$ & 39.0 & 309 & 314 & $73(66)$ & $73(66)$ & (83) & (78) & $7(9)$ \\
\hline $\begin{array}{l}\pi \text { back-bonding only } \\
\text { B. }\left[\mathrm{Fe}(\mathrm{tpp})(\mathrm{ImH})_{2}\right] \\
\quad \mathrm{Fe}(\mathrm{II})\end{array}$ & 39.0 & 309 & 314 & $65(66)$ & $67(66)$ & (83) & (78) & 11(9) \\
\hline $\begin{array}{l}\sigma, \pi \text {-donation }+ \\
\quad \pi \text { back-bonding }\end{array}$ & & & & & & & & \\
\hline $\begin{array}{l}\text { A. }\left[\mathrm{Fe}(\mathrm{tpp})(\mathrm{ImH})_{2}\right] \mathrm{Cl} \\
\quad \mathrm{Fe}(\mathrm{III})\end{array}$ & 38.3 & 303 & 333 & $54(66)$ & $68(62)$ & 93 & $58(71)$ & (2) \\
\hline $\begin{array}{l}\sigma, \pi \text {-donation only } \\
\left.\text { B. [Fe(tpp)(ImH })_{2}\right] \mathrm{Cl} \\
\quad \mathrm{Fe}(\mathrm{III})\end{array}$ & 38.3 & 303 & 333 & $52(66)$ & $68(62)$ & 93 & $57(71)$ & $2(2)$ \\
\hline $\begin{array}{l}\sigma, \pi \text {-donation }+ \\
\quad \pi \text { back-bonding }\end{array}$ & & & & & & & & \\
\hline
\end{tabular}

${ }^{a}$ The $\%$ metal character summed over unoccupied orbitals reflects the combined effects of covalency and back-bonding. In a system with no backbonding, this number divided by the number of holes gives the average $\%$ metal character in each orbital. For example, for $\left[\mathrm{Fe}(\operatorname{tacn})_{2}\right] \mathrm{Cl}_{3}, 351 / 5=70 \%(63$ $\times 4+99) / 5=70 .{ }^{b}$ DFT values for the $\mathrm{d}_{x z}$ - and $\mathrm{d}_{y z}$-orbitals were averaged for comparison to the VBCI model in $D_{4 h}$ symmetry. The values for each orbital are given in Table 1.

Table 4. Parameters for Three Configuration Simulations of $\mathrm{K}_{3}\left[\mathrm{Fe}(\mathrm{CN})_{6}\right], \mathrm{K}_{4}\left[\mathrm{Fe}(\mathrm{CN})_{6}\right],{ }^{50}\left[\mathrm{Fe}(\mathrm{tpp})(\operatorname{ImH})_{2}\right]$, and $\left[\mathrm{Fe}(\mathrm{tpp})(\mathrm{ImH})_{2}\right] \mathrm{Cl}$

\begin{tabular}{|c|c|c|c|c|c|c|c|c|c|c|c|c|c|c|c|}
\hline \multirow[b]{2}{*}{ compound } & \multicolumn{4}{|c|}{$\begin{array}{c}\text { configuration } \\
\text { separations }\end{array}$} & \multicolumn{4}{|c|}{$\begin{array}{l}\text { MLCT mixing } \\
\text { parameters }^{a}\end{array}$} & \multicolumn{4}{|c|}{$\begin{array}{l}\text { LMCT mixing } \\
\text { parameters }^{a}\end{array}$} & \multicolumn{3}{|c|}{$\begin{array}{l}\text { ligand } \\
\text { field }\end{array}$} \\
\hline & EG2 & EF2 & EG3 & EF3 & $\begin{array}{c}d^{5} L^{-}-d^{6} \\
T\left(b^{1}\right)\end{array}$ & $\begin{array}{c}d^{5} L^{-}-d^{6} \\
T\left(a^{1}\right)\end{array}$ & $\begin{array}{c}d^{5} L^{-}-d^{6} \\
T\left(b^{2}\right)\end{array}$ & $\begin{array}{c}d^{5} L^{-}-d^{6} \\
T\left(e^{1}\right)\end{array}$ & $\begin{array}{c}d^{6}-d^{7} L \\
T\left(b^{1}\right)^{-}\end{array}$ & $\begin{array}{c}d^{6}-d^{7} L \\
T\left(a^{1}\right)\end{array}$ & $\begin{array}{c}d^{6}-d^{7} \underline{L} \\
T\left(b^{2}\right)^{-}\end{array}$ & $\begin{array}{c}d^{6}-d^{7} \underline{L} \\
T\left(e^{1}\right)\end{array}$ & $10 \mathrm{Dq}$ & $\mathrm{Dt}$ & Ds \\
\hline $\mathrm{K}_{3}\left[\mathrm{Fe}(\mathrm{CN})_{6}\right]^{50}$ & 1.00 & 0.50 & -1.00 & -1.50 & 0.9 & 0.9 & 2.0 & 2.0 & 1.9 & 1.9 & 0.0 & 0.0 & 3.7 & 0.0 & 0.0 \\
\hline $\mathrm{K}_{4}\left[\mathrm{Fe}(\mathrm{CN})_{6}\right]^{50}$ & 2.06 & 1.56 & 2.00 & 0.00 & 0.8 & 0.8 & 1.6 & 1.6 & 1.7 & 1.7 & 0.0 & 0.0 & 3.9 & 0.0 & 0.0 \\
\hline$\left[\mathrm{Fe}(\mathrm{tpp})(\mathrm{ImH})_{2}\right] \mathrm{Cl}$ & 1.40 & 1.60 & 0.00 & 0.00 & 0.0 & 0.0 & 0.7 & 1.3 & 4.4 & 3.2 & 1.0 & 2.7 & 2.2 & 0.028 & 0.0 \\
\hline$\left[\mathrm{Fe}(\mathrm{tpp})(\mathrm{ImH})_{2}\right]$ & 1.40 & 1.60 & 1.00 & -1.00 & 0.0 & 0.0 & 0.0 & 0.8 & 2.8 & 2.8 & 1.6 & 2.9 & 1.63 & 0.008 & 0.019 \\
\hline
\end{tabular}

${ }^{a}$ These parameters are for the $2 \mathrm{p}^{6}$ initial state and $2 \mathrm{p}^{5}$ final sate. These ligand field parameters, along with $T$ and $\Delta$, will decrease upon going to the final state, and the effects of changing their values in the $2 \mathrm{p}^{5}$ final state have been evaluated (see Figure S9, Supporting Information). It is found that final state changes do not affect the results of the DOC analysis of the initial state in these highly covalent systems. These parameters are defined relative to the $\mathrm{d}^{N-1}$ configuration, i.e., $\mathrm{EG} 1=0$.

Figure 6: the decrease in intensity and shift in energy of the lowest energy peak on the $\mathrm{L}_{3}$-edge. This change alone does not adequately simulate the spectrum of $\left[\mathrm{Fe}(\operatorname{tpp})(\mathrm{ImH})_{2}\right] \mathrm{Cl}$, since the main feature is still too sharp. The closest fit to experiment

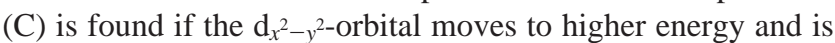

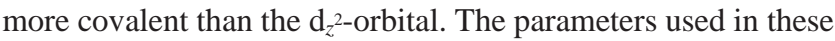
simulations are given in Tables S2 and S3 (Supporting Information).

To interpret the spectral changes in terms of metal-ligand covalency, the best-fit VBCI simulation (Figure 4B) was projected onto the $D_{4 h}$ symmetry components $\left(A_{1 g}, B_{1 g}, E_{g}\right.$, and $B_{2 g}$ ), as described in ref 48 . Table 3 gives the values for covalency derived from both the VBCI analysis and the DFT calculations described above. The VBCI simulation gives the metal characters in the Fe d-orbitals as $\mathrm{d}_{x^{2}-y^{2}}, 52 \% ; \mathrm{d}_{z^{2}}, 68 \%$; and $\mathrm{d}_{x z} / \mathrm{d}_{y z}, 57 \%$ (Table 3 ). Note that, in $D_{4 h}$ symmetry, the $\mathrm{d}_{x z}$ and $\mathrm{d}_{y z}$-orbitals have the same energy and covalency, while in the actual complex, the lower symmetry associated with axial $\pi$-donor ligands localizes the hole in the $\mathrm{d}_{y z}$-orbital. This difference is ascertained from the VBCI model by setting the $e_{g}\left(D_{4 h}\right)$-orbital at the same energy as the $\mathrm{d}_{y z}$ "hole" orbital. The largest differences upon going from non-heme to heme Fe are the increased covalencies in both the $\mathrm{d}_{x^{2}-y^{2}}$ and the $\mathrm{d}_{x z} / \mathrm{d}_{y z^{-}}$

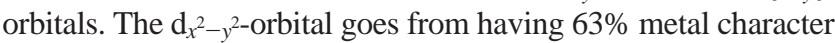
in non-heme tacn to $52 \%$ metal character in the heme complex, which reflects the increased $\sigma$-donation from the porphyrin. The $\mathrm{d}_{x z} / \mathrm{d}_{y z}$-orbital goes from having $99 \%$ metal character in the nonheme tacn ligand system to $50 \%$ metal character in the heme complex, which reflects the substantial $\pi$-donation from both the porphyrin and the axial imidazole. The metal character in the $\mathrm{d}_{z^{2}}$-orbital largely reflects the $\sigma$ covalency of the axial imidazoles, which is similar in the heme and non-heme cases, with around $65 \%$ metal character, which indicates that the $\mathrm{ImH}$ ligand acts as a $\sigma$-donor, of comparable strength to tacn (Table 3).

3.2. Comparison to DFT. The total orbital covalency based on the total L-edge intensity gives $303 \%$ metal character summed over all unoccupied metal orbitals. The DFT calculations (Table 3) give 333\%, which predicts an overall less covalent system than observed experimentally. The experimental differences in the VBCI analysis ( $\pi$-donation into $\mathrm{d}_{y z}$ and $\sigma$-donation into $\mathrm{d}_{x^{2}-y^{2}}$ and $\mathrm{d}_{z^{2}}$ ) are also reflected in the DFT calculations. The ratio of experimental to DFT-calculated metal character for each symmetry set of orbitals (in \%) is $\mathrm{d}_{x^{2}-y^{2}}, 52$ : $62 ; \mathrm{d}_{z}{ }^{2}, 68: 64$; and $\mathrm{d}_{y z}, 52: 71$. The main difference between experiment and the DFT calculation at the BP86 level is the larger relative contribution of $\pi$-donation to $\mathrm{d}_{y z}$ in the data and the larger difference in $\sigma$-donation to $\mathrm{d}_{x^{2}-y^{2}}$ and $\mathrm{d}_{z^{2}}$.

3.3. Evaluation of Possible Back-Bonding. For completeness, a contribution of $\pi$ back-bonding was added to the 

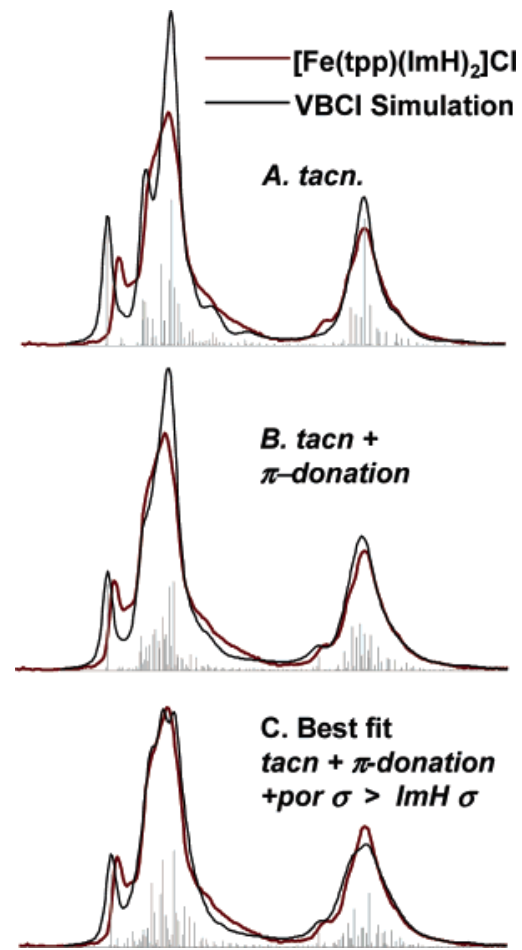

Figure 6. Steps toward the simulation of $\left[\mathrm{Fe}(\mathrm{tpp})(\mathrm{ImH})_{2}\right] \mathrm{Cl}$ L-edge spectra. In each case, the experimental spectrum of $\left[\mathrm{Fe}(\mathrm{tpp})(\mathrm{ImH})_{2}\right] \mathrm{Cl}$ (red) is superposed on a simulated spectrum (gray). (A) The $[\mathrm{Fe}(\operatorname{tacn})] \mathrm{Cl}_{3}$ simulation from ref 33. (B) The addition of $\pi$-donation into $\mathrm{d}_{x z} / \mathrm{d}_{y z}$ to simulation A. (C) The best fit of $\left[\mathrm{Fe}(\mathrm{tpp})(\mathrm{ImH})_{2}\right] \mathrm{Cl}$, which incorporates both differences in the covalency of $\mathrm{d}_{x^{2}-y^{2}}$ and $\mathrm{d}_{z^{2}}$, as well as the effects of $\pi$-donation into $\mathrm{d}_{x z} / \mathrm{d}_{y z}$.

simulation of the spectrum of the low-spin $\mathrm{Fe}(\mathrm{III})$ heme complex. If a small contribution of back-bonding $(\sim 2-3 \%)$ is added, slightly better agreement with experiment is observed; the spectrum changes shape to higher energy, as indicated by the red arrow in Figure S4A (Supporting Information). If more back-bonding is added ( $>4 \%)$, the spectral shape is inconsistent with the experimental spectrum. These observations indicate that back-bonding from $\mathrm{Fe}(\mathrm{III})$ into the $4 e_{g}\left(D_{4 h}\right) \pi^{*}$-orbitals of the porphyrin is very limited, which is consistent with earlier conclusions from NMR spectroscopy. ${ }^{29,42}$ When the simulation that includes both $\pi$ back-bonding and $\sigma$ - and $\pi$-donation is split into its symmetry components, it gives differential orbital covalencies very similar to those reported above for $\mathrm{Fe}(\mathrm{III})[\mathrm{Fe}-$ $\left.(\operatorname{tpp})(\operatorname{ImH})_{2}\right] \mathrm{Cl}$, in which the effects of back-bonding were not included (Table 2). This is consistent with the DFT calculations, which indicate very limited $(2 \%)$ back-bonding in the low-spin $\mathrm{Fe}(\mathrm{III})$ heme complex.

\section{Discussion}

The d manifold in heme compounds has been very difficult to study experimentally because the porphyrin-based $\pi \rightarrow \pi^{*}$ transitions obscure the metal-based transitions. In this study, we have applied Fe L-edge X-ray absorption spectroscopy at the $\mathrm{L}_{3}$ - and $\mathrm{L}_{2}$-edges to directly probe the Fe d-orbitals of heme complexes and quantify the $\sigma$ - and $\pi$-donor as well as $\pi$-acceptor contributions to bonding.

Figure 7 compares the $\mathrm{L}_{3}$-edge spectrum of an $\mathrm{Fe}(\mathrm{III})$ nonheme reference complex, $\left[\mathrm{Fe}(\operatorname{tacn})_{2}\right] \mathrm{Cl}_{3}$, to that of the $\mathrm{Fe}(\mathrm{III})$ site in $\left[\mathrm{Fe}(\mathrm{tpp})(\mathrm{ImH})_{2}\right] \mathrm{Cl}$. The set of spectra are given twice: to the left the non-heme is colored and the heme is in gray, and

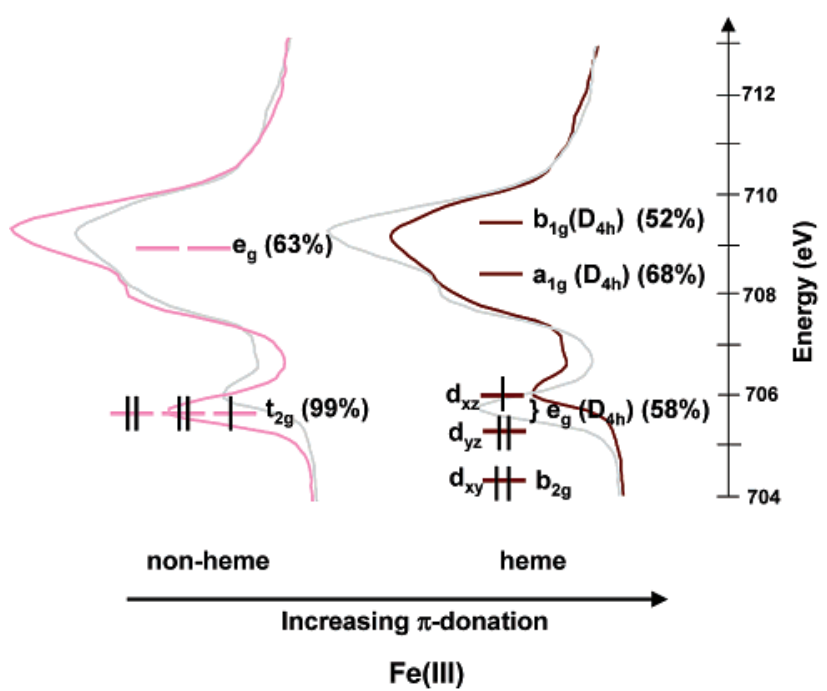

Figure 7. Fe d-orbital energy levels superimposed on the $\mathrm{L}_{3}$ spectra of $\left[\mathrm{Fe}(\operatorname{tacn})_{2}\right] \mathrm{Cl}_{3}$ and $\left[\mathrm{Fe}(\mathrm{tpp})(\mathrm{ImH})_{2}\right] \mathrm{Cl}$. The $\%$ metal character in the d-orbitals calculated, from a combination of spectral simulations and total intensity, is given in parentheses.

to the right the reverse. Superimposed on the spectra are the orbital energies and the \% metal character in each orbital, calculated from a combination of total intensity and VBCI analysis of spectral shape, as discussed in the Analysis section. The line offset from the orbitals compares the weighted average energy of the d-manifold intensity. The feature arising from the $2 \mathrm{p}^{6} t_{2 g}{ }^{5} \rightarrow 2 \mathrm{p}^{5} t_{2 g}{ }^{6}$ transition (the $t_{2 g}$ feature) is indicated.

From Figure 7 , it is clear that the $t_{2 g}$ feature is both closer in energy to the main multiplet packet and much lower in intensity in a heme relative to non-heme environment. This difference is due to the effect of strong $\pi$-donation perpendicular to the plane of the porphyrin, which shifts the heme $\mathrm{Fe} \mathrm{d}_{x z} / \mathrm{d}_{y z}\left(e_{g}\right)$ orbitals to higher energy and decreases the metal character, thus decreasing the intensity of the $t_{2 g}$ feature. ${ }^{101}$ These observations have been quantified using the VBCI model, which allows the separation of multiplet and ligand field effects from those of covalency on spectral shape.

In addition to the significant $\pi$-donation, we also find that the heme ligand set acts as a strong $\sigma$-donor relative to amine ligation. This is evident from the Fe(III) L-edge in three ways: the energy shift, the total intensity, and the spectral shape. The spectra of both heme and tacn Fe(III) have the same energy shift, yet the heme spectrum has lower intensity (Figure 7). The difference in intensity indicates that the effective nuclear charge on the Fe(III) is lower in the heme complex. In the absence of other effects, this difference in $Z_{\text {eff }}$ would shift the heme spectrum to lower energy. However, because there is no difference in energy, there must be a ligand field contribution dominated by $\sigma$ bonding that opposes the energy change of $Z_{\text {eff. }}$. From the VBCI model, the change in shape of the main multiplet

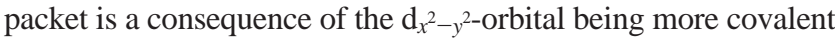
than the $\mathrm{d}_{z^{2}}{ }^{2}$-orbital, indicating that the heme ligand is a stronger $\sigma$-donor than the axial imidazole ligand, resulting in a tetragonal anisotropy of the $\sigma$ bonding.

Figure 8 shows three sets of low-spin Fe(II) spectra: spectrum $\mathrm{a}$ is that of non-heme $\left[\mathrm{Fe}(\operatorname{tacn})_{2}\right] \mathrm{Cl}_{2}$, spectrum $\mathrm{b}$ is that of the

(101) This is $y z$ and, from DFT calculations, has $3 \% \operatorname{ImH} \pi$ character

(102) Thole, B. T.; van der Laan, G. Phys. Rev. B 1988, 38, 3158-3170. 


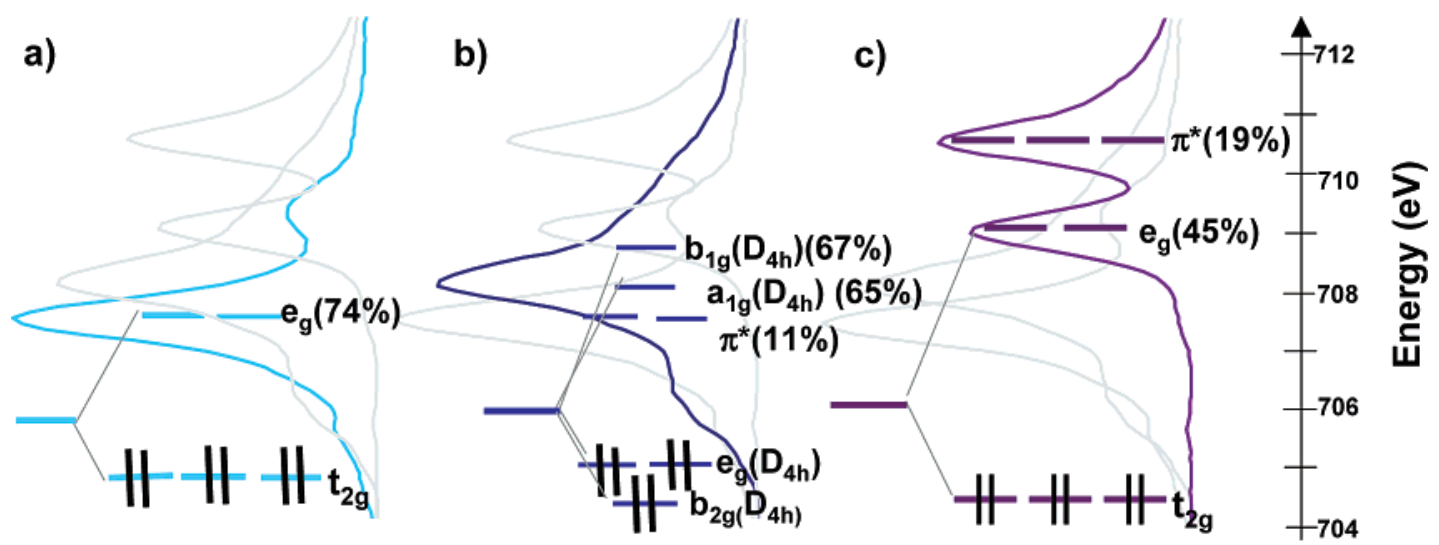

Figure 8. Fe d-orbital energy levels superposed on the $\mathrm{L}_{3}$ spectra of (a) $\left[\mathrm{Fe}(\operatorname{tacn})_{2}\right] \mathrm{Cl}_{2}$, (b) $\left[\mathrm{Fe}(\operatorname{tpp})(\operatorname{ImH})_{2}\right]$, and $(\mathrm{c}) \mathrm{K}_{4}\left[\mathrm{Fe}(\mathrm{CN})_{6}\right]$. The \% covalencies, calculated from a combination of spectral simulations and total intensity, are given in parentheses. In each case, all three spectra are given; the spectra shown in gray are included for reference.

heme compound [Fe(tpp)(ImH $)_{2}$ ], and spectrum $\mathrm{c}$ is that of $\mathrm{K}_{4}$ $\left[\mathrm{Fe}(\mathrm{CN})_{6}\right] .{ }^{50}$ As in Figure 7, the set of three spectra is repeated in gray for reference to one another, and the \% metal character in each orbital obtained from experiment is given in parentheses.

As for the low-spin Fe(III) heme complex, the effects of strong $\sigma$-donation by the porphyrin are evident in the $\mathrm{Fe}$ (II) L-edge spectra from the spectral shift and total intensity. The spectrum of the Fe(II) heme complex shifts $0.7 \mathrm{eV}$ to higher energy relative to the spectrum of the $\mathrm{Fe}$ (II) non-heme complex. However, their total intensities, and therefore $Z_{\mathrm{eff}}$, are about the same for heme relative to non-heme, which indicates that the larger ligand field due to strong $\sigma$-donation of the heme shifts the transitions to the $\mathrm{d}_{x^{2}-y^{2}}$ and $\mathrm{d}_{z^{2}}$-orbitals to higher energy, as indicated in Figure $8 \mathrm{a}\left(e_{g}\right.$, in $\left.D_{4 h}\right)$ and $8 \mathrm{~b}\left(a_{1 g}\right.$ and $\mathrm{b}_{1 \mathrm{~g}}$, in $\left.D_{4 h}\right)$.

The addition of back-bonding into the ligand $\pi^{*}$-orbitals can have a significant effect on both the Fe L-edge spectral shape and total intensity. Since the Fe L-edge results from transitions to the unoccupied Fe d-orbitals, the mixing of occupied metal character into the unoccupied ligand $\pi^{*}$-orbitals provides an additional intensity pathway. Further, CI mixing between the metal unoccupied $e_{g}\left(D_{4 h}\right)$ - and $\pi^{*}$-orbitals due to back-bonding changes the spectral shape. If we first compare the tacn to the $\mathrm{CN}^{-}$spectra (spectrum a to c), a significant difference is observed, as the spectrum of $\mathrm{K}_{4}\left[\mathrm{Fe}(\mathrm{CN})_{6}\right]$ has a second main feature that has been assigned as arising from a transition to the ligand $\pi^{*}$-orbital. This transition borrows intensity from the main transition to the $e_{g}$ set of d-orbitals, to make the contribution of the ligand $\pi^{*}$ very pronounced. ${ }^{50}$ In going from $\left[\mathrm{Fe}(\operatorname{tacn})_{2}\right] \mathrm{Cl}_{2}$ to $\left[\mathrm{Fe}(\mathrm{tpp})(\mathrm{ImH})_{2}\right]$ (spectra a and b), the spectrum becomes broader but does not show the pronounced $\pi^{*}$ peak of the $\mathrm{CN}^{-}$. This broadening is a consequence of the addition of a small amount of $\pi^{*}$ intensity in an orbital located close in energy to the main $e_{g}$-orbital set. ${ }^{50}$ Thus, there is back-bonding in the $\mathrm{Fe}^{\mathrm{II}}$ heme complex, but it is much less than in ferrocyanide (11(2)\% vs $19(3) \%) .{ }^{50}$

The rather limited metal character in the $\pi^{*}$-orbital reflects the fact that the heme ligand does not act as a particularly good $\pi$-acceptor, yet the porphyrin $\pi^{*}$-orbital is closer in energy to the d-orbitals than the $\mathrm{CN}^{-} \pi^{*}$-orbitals in ferrocyanide. This reflects the fact that the heme system $4 e_{g}\left(D_{4 h}\right) \pi^{*}$-orbital contains small nitrogen orbital coefficients, so it does not substantially overlap with the metal. For comparison, DFT calculations show that the $\mathrm{CN}^{-} \pi^{*}$-acceptor orbitals have about
$60 \%$ total carbon character, whereas the heme $\pi^{*}$-acceptor orbitals have only $30 \%$ total nitrogen character. In the Fe(III) heme system, when more than $2 \%$ back-bonding was included in the VBCI simulation, either the spectrum became too broad or an additional peak appeared, which indicates that the backbonding from $\mathrm{Fe}$ (III) to heme is not significant. Upon going from $\mathrm{Fe}(\mathrm{II})$ to $\mathrm{Fe}(\mathrm{III})$, the d-orbitals contract and decrease in energy, due to the increase in $Z_{\text {eff }}$, and thus lead to the very low back-bonding observed both experimentally and from DFT calculations.

Understanding the degree and origin of the $\pi$ delocalization of heme systems has important implications for understanding the reactivity of heme centers in biology. The fast electrontransfer rates in proteins are facilitated by superexchange coupling through either hole or electron superexchange pathways which enhance the interactions between donor and acceptor redox sites. ${ }^{103-105}$ For a superexchange mechanism to be efficient, the redox-active MO must have sufficient delocalization through the protein. In the cytochromes, a hole superexchange mechanism would be facilitated by a strong $\pi$-donor interaction of the heme $3 e_{g}$-orbital with the $\mathrm{d}_{y z}$ hole of the oxidized Fe(III) site. An electron superexchange mechanism requires substantial mixing of the reduced $\mathrm{Fe}(\mathrm{II})$ valence d-orbitals with the heme $4 e_{g}$-orbital through $\pi$ back-bonding. In this study, we have experimentally quantified the $\pi$-donation to $\mathrm{Fe}$ (III) and the $\pi$ back-bonding from $\mathrm{Fe}(\mathrm{II}) . \pi$-donation to low-spin $\mathrm{Fe}(\mathrm{III})$ produces a redox-active molecular orbital that is $50 \%$ metal and $50 \%$ ligand, whereas $\pi$ back-bonding from $\mathrm{Fe}(\mathrm{II})$ produces an HOMO which has $90 \%$ metal and $10 \%$ ligand character. The coefficients of mixing indicate that a hole superexchange mechanism likely dominates.

Thus, the interaction of the $d_{\pi}$ redox-active ferric molecular orbital (RAMO) with the $3 e_{g} \pi$ heme donor orbitals determines the hole superexchange pathway. In the limit when no axial ligands are attached to the $\mathrm{Fe}$ in the porphyrin, the $\mathrm{d}_{x z^{-}}$and $\mathrm{d}_{y z}$-based orbitals are degenerate and equally mix with the porphyrin $3 e_{g}$-orbitals. In a "real" system, this degeneracy will be lifted through axial $\pi$ bonding interactions or through distortions either in the plane or from the plane of the porphyrin. If two eclipsed ImH ligands are bound to heme, the $\mathrm{ImH}$ $\pi$-donor orbitals (perpendicular to the ImH plane) interact with

(103) Gray, H. B.; Winkler, J. R. Annu. Rev. Biochem. 1996, 65, 537-561 (104) Newton, M. D. J. Phys. Chem. 1988, 92, 3049-3056.

(105) Newton, M. D. Chem. Rev. 1991, 91, 767-792. 


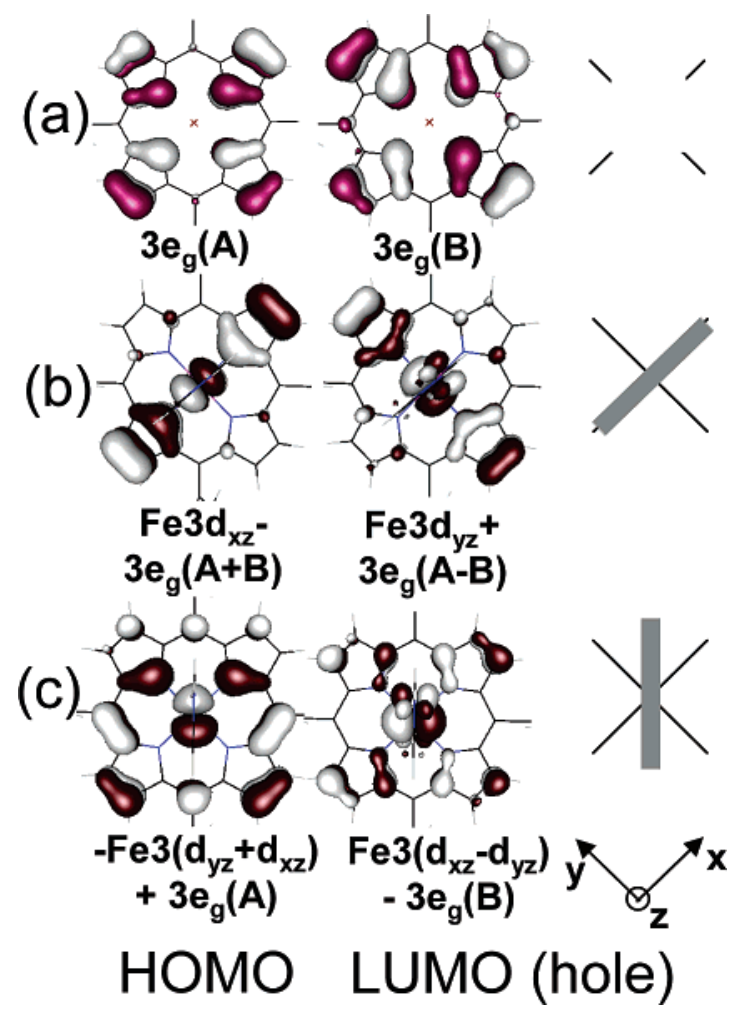

Figure 9. Porphyrin delocalization as a function of axial ligand orientation. (a) The two degenerate porphyrin $3 e_{g}$-orbitals, labeled $\mathrm{A}$ and $\mathrm{B}$. The delocalization of the HOMO and LUMO orbitals and their coefficients (b) when the ImH ligands are eclipsed and oriented along the $y$-axis and (c) when the ImH ligands are eclipsed and bisect the $x$ - and $y$-axes. The ImH $\pi$-orbitals can be seen above and below the porphyrin plane in the LUMO. To the right, the gray rectangles intersecting the black cross indicate the orientation of the axial imidazoles relative to the porphyrin ring.

only one $\mathrm{d}_{\pi}$-orbital, and this will localize the RAMO $\mathrm{d}_{\pi}$ hole. Figure 9a shows the two degenerate porphyrin $\pi$-donor $3 e_{g}$ $\left(D_{4 h}\right)$-orbitals, labeled A and $\mathrm{B}$. When the imidazoles are oriented with their molecular planes in the $x z$ plane (i.e., the plane along $\mathrm{N}-\mathrm{Fe}-\mathrm{N}$ axis), as in Figure $9 \mathrm{~b}$, the LUMO localizes into the $\mathrm{Fe} 3 \mathrm{~d}_{y z}+3 e_{g}(\mathrm{~A}-\mathrm{B})$ combination, creating a highly directional MO for superexchange. If the $\mathrm{ImH}$ ligands are eclipsed but rotated such that their planes are no longer along the $\mathrm{N}-\mathrm{Fe}-\mathrm{N}$ axis, these coefficients change. ${ }^{106}$ When they bisect the $\mathrm{N}-\mathrm{Fe}-\mathrm{N}$ porphyrin angle (Figure $9 \mathrm{c}$ ), the $3 e_{g}\left(D_{4 h}\right)$ mixed into the LUMO is delocalized over the porphyrin. Finally, if the $\mathrm{ImH}$ ligands are staggered (perpendicular to each other), each $\operatorname{ImH}$ ligand $\pi$-donates into a different $\mathrm{d}_{\pi}$-orbital, and the effective orbital symmetry is $D_{4 h}$. In such a case, the system will be unstable to a symmetry-breaking distortion of the heme plane. These effects of axial ligand orientation have been discussed elsewhere in terms of NMR experiments, ${ }^{29,30,41,42,106}$ crystallography, ${ }^{107}$ and DFT calculations. ${ }^{108-113}$

(106) Shokhirev, N. V.; Walker, F. A. J. Biol. Inorg. Chem. 1998, 3, 581-594.

(107) Collins, D. M.; Countryman, R.; Hoard, J. L. J. Am. Chem. Soc. 1972, 94, 3301-3312.

(108) Rydberg, P.; Sigfridsson, E.; Ryde, U. J. Biol. Inorg. Chem. 2004, 9, $203-$ 223.

(109) Loew, F. Int J. Quantum Chem 2000, 77, 54-70.

(110) Soltis, S. M.; Strouse, C. E. J. Am. Chem. Soc. 1988, 110, 2824-2829

(111) The other contributions to porphyrin distortions include steric effects and the changes in porphyrin delocalization caused by the different ring substitutents.

(112) Scheidt, W. R.; Chipman, D. M. J. Am. Chem. Soc. 1986, 108, 11631167.

(113) Sturge, M. D. Solid State. Phys. 1967, 20, 91-210. (a) Cyt $b_{5}---H i s-H i s$
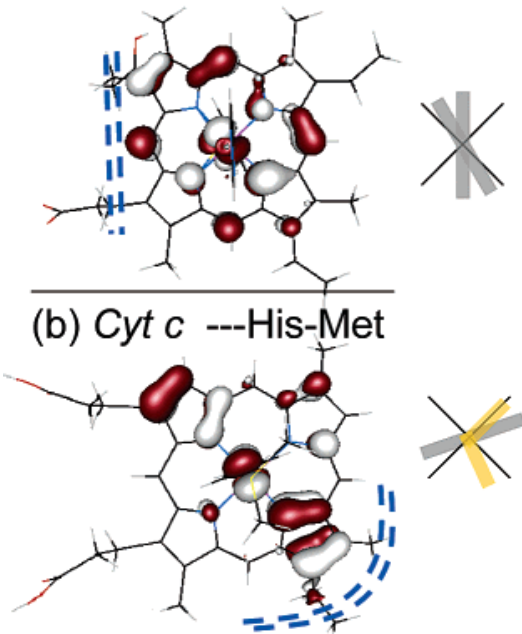

Figure 10. LUMO orbitals (hole) calculated for the active site of (a) the bis-histidine-ligated heme bovine microsomal cytochrome $b_{5}$ (PDB code $1 \mathrm{CYO})^{114}$ and (b) the histidine-methionine-ligated bovine heart cytochrome $c$ (PDB code 1B4Z). ${ }^{115,116}$ The gray rectangles relative to the black cross indicate the orientation of the $\mathrm{ImH}$ ligands to the heme, projected into the $x y$ heme plane. The methionine sulfur is at the intersection of the two short yellow rectangles in (b). Dashed blue lines indicate the most exposed part of the heme edge of these two structures.

Extension of these axial ligand effects on the LUMO to heme sites in proteins provides some insights into superexchange contributions to electron transfer. While there are many different axial ligand orientations observed in the cytochromes, two interesting cases are considered in Figure 10. Figure 10a shows the LUMO calculated with ImH oriented as in the cytochrome $b_{5}$ family. ${ }^{117-119}$ This orbital shows substantial delocalization along the heme edge. Figure 10b shows the LUMO calculated from bovine heart $(\mathrm{BH})$ cytochrome $c(1 \mathrm{~B} 4 \mathrm{Z})$, which has an axial methionine oriented between the $\mathrm{N}-\mathrm{Fe}-\mathrm{N}$ bond and the plane formed by the $\mathrm{C}-\mathrm{S}-\mathrm{C}$ atoms of the methionine that is tilted approximately $45^{\circ}$ to the heme normal. In this orientation, the methionine can provide both $\sigma$ - and $\pi$-down interactions with the Fe through its $a_{1}$ - and $b_{1}$-orbitals, respectively. ${ }^{120}$ In a single-point calculation (i.e., a calculation using the crystal structure coordinates of $\mathrm{BH}$ cytochrome $c$ active site, from Figure 10b), the LUMO has a different pattern of delocalization relative to cytochrome $b_{5}$, with higher coefficients on one set of $\beta$-pyrrole carbons. The differences in delocalization between the LUMO in cytochrome $b_{5}$ and $\mathrm{BH}$ cytochrome $c$ are consistent with the differences in the orientation of the heme groups relative to the surface of the proteins. In cytochrome $b_{5}$, the $\beta$ and meso positions along one edge (the edge containing the two propionates) are equally exposed, whereas in $\mathrm{BH}$ cytochrome $c$, one of the sets of $\beta$-pyrrole carbons is most

(114) Durley, R. C. E.; Matthews, F. S. Acta Crystallogr., Sect. D 1996, 52 $65-76$.

(115) Mirkin, N.; Jakoncic, J.; Stonjanoff, V.; Moreno, A. To be published, structure deposited in Protein Data Bank 2005.

(116) For other cytochromes $c$, the orientation of the methionine methyl can vary by more than $90^{\circ}$ and thus adjust the nodal plane of the methionine sulfur by more than $45^{\circ}$.

(117) The Protein Data Bank (http://www.pdb.org/).

(118) Bernstein, F. C.; Koetzle, T. F.; Williams, G. J.; Meyer, E. F., Jr.; Brice, M. D.; Rodgers, J. R.; Kennard, O.; Shimanouchi, T.; Tasumi, M. J. Mol. Biol. 1977, 112, 535-542

(119) Zaric, S. D.; Popovic, D. M.; Knapp, E.-W. Biochemistry 2001, 40, 79147928.

(120) Holm, R. H.; Kennepohl, P.; Solomon. E. I. Chem. Rev. 1996, 96, 22392314 
exposed (including one of the covalent thioether attachments to the protein). These differences are indicated by the dotted blue lines in Figure 10. Thus, for both cytochrome $b_{5}$ and $\mathrm{BH}$ cytochrome $c$, the hole superexchange pathways are directed to the most exposed part of the heme edge, consistent with experiments which indicate that electron transfer occurs at the exposed heme edge. ${ }^{119,121}$

In a recent study, the relative reactivity of an $\mathrm{Fe}^{\mathrm{IV}}=\mathrm{O}$ heme was compared to that of an $\mathrm{Fe}^{\mathrm{IV}}=\mathrm{O}$ non-heme complex. ${ }^{122}$ While the $\mathrm{Fe}-\mathrm{O}$ bonding of the heme and non-heme systems were found to be similar, the calculations showed that the reaction energy for $\mathrm{H}$-atom abstraction favored the heme system by $\sim 10 \mathrm{kcal} / \mathrm{mol}$. This was attributed to electron delocalization in the $\mathrm{Fe}^{\mathrm{III}}-\mathrm{OH}$ product in the heme environment. From our studies here, the low-spin ferric heme has extensive electron delocalization due to heme $\pi$-donation. This could contribute in reactions where Compound II (i.e., $\mathrm{Fe}^{\mathrm{IV}}=\mathrm{O}$ ) may be catalytically relevant.

\section{Summary}

In this study, we have been able to experimentally quantify the effects of $\pi$-donation and $\pi$ back-bonding for a highly covalent $\mathrm{Fe}$ center in a porphyrin environment. We find that the heme ligand acts as a very strong $\pi$-donor to $\mathrm{Fe}$ (III) and a weak $\pi$-acceptor from $\mathrm{Fe}(\mathrm{II})$. The relative strengths of the $\pi$-donation vs $\pi$-acceptor interactions indicate that electron transfer in the cytochromes likely involves a hole-type superexchange mechanism that is facilitated by the very strong

(121) We note that heme centers in biology are very diverse, there are many bacterial cytochromes $c$, some of which have bis-histidine-coordinated hemes while others have histidine-methionine-coordinated hemes, and their structures vary from being similar to the bovine heart His-Met cytochrome $c$ shown here to being similar to cytochrome $b_{5}$.

(122) Decker, A.; Solomon, E. I. Angew. Chem., Int. Ed. 2005, 44, 2252-2255. $\pi$-donation from porphyrin to $\mathrm{Fe}(\mathrm{III})$. This strong heme $\pi$-donation can also play an important role in stabilizing $\mathrm{Fe}(\mathrm{III})$ in catalytic cycles.

Acknowledgment. This work was supported by grants from the NIH GM-40392 and NSF CHE-0446304 to E.I.S., NIH RR01209 to K.O.H., NIH DK-31038 to F.A.W., and NIH GM69568 to James P. Collman (which supported Y.Y.). This work was performed at SSRL, which is funded by the U.S. Department of Energy (DOE) Office of Basic Energy Sciences. The SSRL Structural Molecular Biology Program is supported by the NIH National Center for Research Resources, Biomedical Technology Program, and by the DOE Office of Biological and Environmental Research. R.K.H. thanks Dr. Serena DeBeer George and Ms. Ritimukta Sarangi for their help in learning beam line operations at SSRL, and Dr. Andrea Decker and Mr. Abhishek Dey for many useful discussions.

Supporting Information Available: Complete ref 73; heme orbitals calculated in rigorous $D_{4 h}$ symmetry, $\mathrm{ImH}$ orbitals calculated in $C_{1}$ symmetry, and tetraphenyl porphyrin orbitals calculated in $C_{i}$ symmetry; effects of back-bonding on the spectra of $\left[\mathrm{Fe}(\mathrm{tpp})(\mathrm{ImH})_{2}\right] \mathrm{Cl}$; table of input parameters and covalencies for simulations $\mathrm{A}$ and $\mathrm{C}$ given in Figure 6; comparison of the energy levels in $\mathrm{Fe}(\mathrm{II})$ heme vs non-heme $\left[\mathrm{Fe}(\mathrm{tpp})(\mathrm{ImH})_{2}\right]($ an expansion of Figure 2); comparison of the energy levels in $\mathrm{Fe}(\mathrm{III})$ heme vs non-heme $\left[\mathrm{Fe}(\mathrm{tpp})(\mathrm{ImH})_{2}\right] \mathrm{Cl}$ (an expansion of Figure 3); expansion of the contents of Table 2; comparison of the relative energy levels in tpp ${ }^{2-}$ and $\mathrm{CN}^{-}$; atomic parameters for spectral simulations; and figure showing the effects of final state parameter changes (reducing ligand field, $T$, and $\Delta$ ). This material is available free of charge via the Internet at http://pubs.acs.org.

JA065627H 